\title{
Propagation and dissipation of internal tides in the Oslofjord
}

\author{
A. Staalstrøm ${ }^{1,2}$, E. Aas ${ }^{2}$, and B. Liljebladh ${ }^{3}$ \\ ${ }^{1}$ Section for Oceanography, Remote Sensing and Marine Modelling, Norwegian Institute for Water Research, Oslo, Norway \\ ${ }^{2}$ Department of Geosciences, University of Oslo, Oslo, Norway \\ ${ }^{3}$ Department of Earth Sciences, University of Gothenburg, Gothenburg, Sweden
}

Correspondence to: A. Staalstrøm (ans@niva.no)

Received: 22 December 2011 - Published in Ocean Sci. Discuss.: 30 January 2012

Revised: 1 June 2012 - Accepted: 15 June 2012 - Published: 19 July 2012

\begin{abstract}
Observations of velocity, pressure, temperature and salinity in the inner Oslofjord have been analysed to provide new information about the relationships between internal tides generated by tidal currents across the Drøbak Sill and dissipation and diffusivity in the fjord.

The most energetic vertical displacement of density surfaces inside the sill is associated with the first internal mode that has maximum amplitude around sill depth. The amplitude of the vertical displacement around sill depth correlates with the amplitude of the surface elevation, and, at a distance of $1 \mathrm{~km}$ inside the sill, the ratio between the amplitudes is 38 , decreasing to 11 at a distance of $10 \mathrm{~km}$. The greatest vertical displacements inside the sill, however, are found at $40 \mathrm{~m}$ depth. These latter internal waves are not associated with a first-mode internal tide, but are rather associated with higher internal modes controlled by stratification.

The energy flux of the internal wave propagating from the Drøbak Sill into the inner fjord on the east side of the Håøya Island is estimated to vary in the range $155-430 \mathrm{~kW}$. This is the same order of magnitude as the estimated barotropic energy loss over the Drøbak Sill $(250 \mathrm{~kW})$, but only 4-10\% of the total barotropic flux. Approximately $40-70 \%$ of the internal energy flux is lost within a distance of $10 \mathrm{~km}$ from the sill. The mean diffusivity below $90 \mathrm{~m}$ depth in this area $\left(\sim 20 \mathrm{~cm}^{2} \mathrm{~s}^{-1}\right)$ is more than four times higher than in the rest of the fjord $\left(\sim 5 \mathrm{~cm}^{2} \mathrm{~s}^{-1}\right.$ or less).
\end{abstract}

\section{Introduction}

The objective of this paper is to obtain more information about the relationships between barotropic tides and the vertical diffusion in the basin waters of a sill fjord like the
Oslofjord. The motivation for the investigation is that the magnitude of the vertical diffusion determines the frequency of deep water renewals in closed basins. While the density of the deep basin waters increases during deep water renewals, the vertical diffusivity reduces the same density by mixing the lighter waters of shallower layers with the heavier waters below. Gade (1967) showed how the density of the deep basin water in the Oslofjord (Fig. 1a) is slowly reduced due to vertical diffusion between abrupt deep water renewals.

Thorpe (2005) lists four ways by which the tidal energy entering a sill fjord may be lost: reflection of energy from the fjord system back to the open sea as a barotropic wave; loss of energy by the work against the bottom shear stress, particularly over the sill; the generation and maintenance of eddies at the sill; and the generation of internal waves that carry energy into the fjord. Wind stress, wind waves and vertical convection will produce mixing in the surface layer, and Kullenberg $(1968,1971)$ used rhodamine B experiments in the Oslofjord to express the vertical diffusivity of the surface layer as a function of wind velocity, density stratification and vertical current shear. Shear stress caused by bottom currents will have a similar effect on the waters close to the bottom. Both of these mechanisms produce more homogeneous water masses near the surface and bottom, while the stratification at mid-depths may be strengthened and actually counteract the mixing process at these depths.

Tidal surface waves can provide the energy required for the mixing in the interior of the water mass. Stigebrandt $(1976,1979,1999)$ based his studies of internal waves in the inner Oslofjord on observations of surface elevation, moored current meters and hydrographic data, and he suggested that the vertical diffusion in sill fjords might be driven by internal waves, due to the breaking of these waves at sloping bottoms. 
(a)

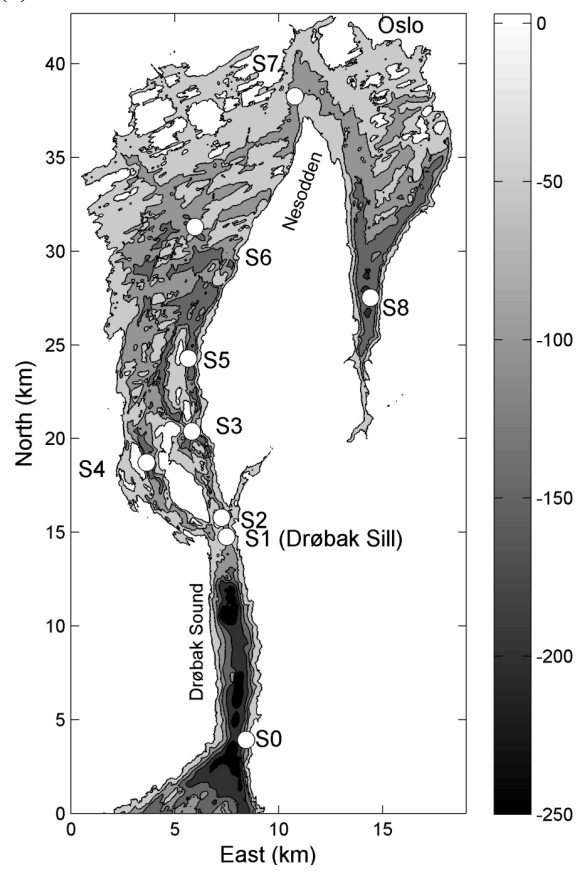

(b)

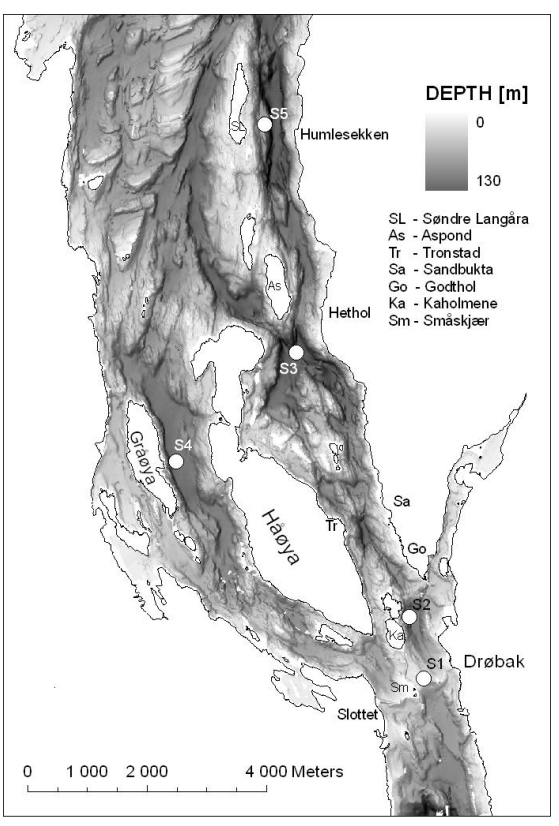

Fig. 1. (a) Map of the inner Oslofjord. Depth contours are drawn for every 50 meters. Moorings were deployed at station S0 (Brenntangen), S1 (Drøbak Sill), S2 (Kaholmen) and S5 (Søndre Langåra). Stations S3, S4, S5, S6, S7 and S8 marked with white circles are standard hydrographic stations from the monitoring program. (b) Map of the area around the Drøbak Sill. Bathymetric data are from the Geological Survey of Norway (Lepland et al., 2009). A grey scale indicates the depths down to 130 meters. A hillside shade effect is used to emphasize the bathymetric structure. Stations are marked with grey circles. The subsurface Drøbak Jetty runs from Kaholmen to Småskjær and further to Slottet on the west side of the sound. The Drøbak Sill $(19.5 \mathrm{~m})$ is located between Småskjær and Drøbak. There is a sill between Kaholmen and Godthol (47 m) and another one between Tronstad and Sandbukta $(62 \mathrm{~m})$.

The mixed waters would flow back to the interior of the fjord as density currents.

The first described observation of internal waves in a sill fjord was made by Petterson at Bornö Hydrographical Station in the Gullmar Fjord on the west coast of Sweden (Zeilon, 1913), while Gade (1967) was the first to report similar waves in the Oslofjord. Internal waves have also been reported in many other sill fjords, for instance the Scottish fjord Loch Etive (Inall and Rippeth, 2002; Inall et al., 2004; Stashchuk et al., 2007) or the Canadian fjord Knight Inlet (Farmer and Smith, 1978, 1979, 1980; Gargett, 1979; Farmer and Armi, 1999; Afanasyev and Peltier, 2001; Armi and Farmer, 2002; Stacey, 2005). Internal waves and vertical diffusion in other Norwegian Fjords have been discussed by Sælen (1948), Fjeldstad (1964), Stigebrandt (1980), Stigebrandt and Aure (1989), Gade and Edwards (1995), and Johnsson et al. (2007). For earlier reviews of mixing, vertical diffusion and other physical processes in fjords, see e.g. Freeland et al. (1980), Farmer and Freeland (1983), Gade et al. (1983) and Svendsen (1986). A recent review of fjord physics has been presented by Inall and Gillibrand (2010).

The average elevation of the sea surface inside the Drøbak Sill (Fig. 1b) in the Oslofjord from low to high tide is $0.3 \mathrm{~m}$, and, since the area of this surface is $1.9 \times 10^{8} \mathrm{~m}^{2}$, the to- tal barotropic energy flux into the inner fjord between low and high water becomes approximately $4000 \mathrm{~kW}$. The first step in relating this energy to the work against buoyancy inside the sill is to establish a relationship between the surface tides and the internal tides created when barotropic currents flow over the Drøbak Sill. Zeilon (1912) demonstrated that a barotropic flow over a sill creates a baroclinic internal wave in a stratified fluid, and Stigebrandt (1976) showed that there is a linear relationship between the amplitude of a surface tidal wave (forcing) and the amplitude of an internal tidal wave (response) in a two-layer sill fjord model. In the present paper, we will investigate this relationship by analysing new observations of surface elevation and vertical displacement of density surfaces inside the Drøbak Sill in the Oslofjord.

In the Gullmar fjord, it was found that as much as $77 \%$ of the internal wave energy is dissipated near the sill (Arneborg and Liljebladh, 2001a,b, Arneborg et al., 2004), and it was suggested that this is due to reflection of internal tides at the fjord head (Arneborg and Liljebladh, 2009). In the Knight Inlet, it was estimated that approximately two thirds of the barotropic energy loss radiates away from the sill as internal waves (Klymak and Gregg, 2004), and in the Scottish fjord Loch Etive, a tracer experiment showed indirectly that dissipation also took place at the sloping bottom in the inner 


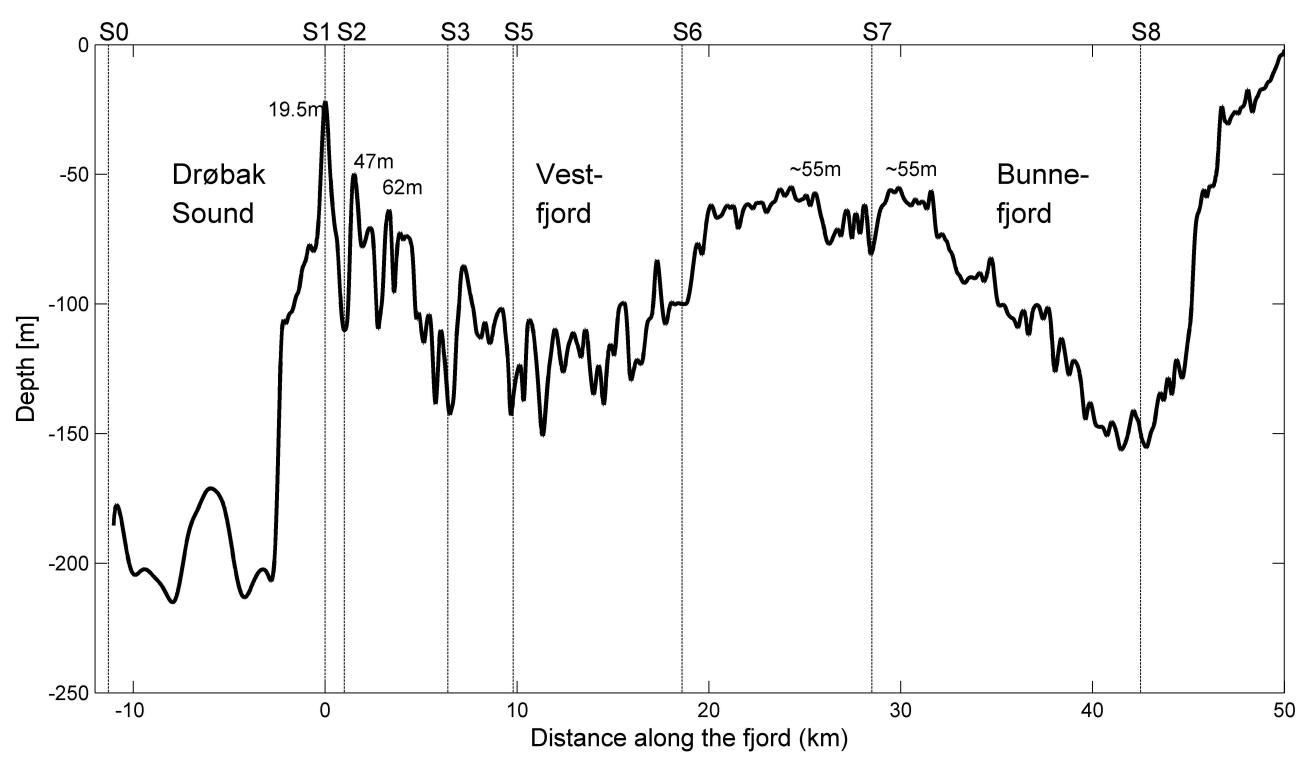

Fig. 2. Depth profile along the fjord following the deepest parts from the Drøbak Sound, on the east side of Håøya Island to the inner parts of the Bunnefjord. Vertical dashed lines indicate the positions of the stations along this line. The most important sills - the Drøbak Sill (19.5 m), the Godthol Sill $(47 \mathrm{~m})$, the Tronstad Sill $(62 \mathrm{~m})$ and the two sills between the Vestfjord and the Bunnefjord (55 $\mathrm{m})$ - are marked with their depths.

parts of the fjord (Inall, 2009). To quantify the energy loss of the internal tide in the inner Oslofjord as it propagates away from the creation area, the baroclinic currents and stratification is observed at stations placed at different distances from the sill.

The energy lost from the mean flow to turbulent flow is basically transformed to heat through dissipation or work against buoyancy through diffusivity (e.g. Osborn, 1980; Svendsen, 1986). In the present study, we will investigate the mean diffusivities of different basins and their relationship to the corresponding estimated losses of baroclinic energy.

The paper is outlined as follows: Sect. 2 describes the area of investigation, the field measurements and databases, and Sect. 3 looks at the propagation of the internal tides, their phase speeds and amplitudes. In Sect. 4, it is estimated how much energy these internal waves are transporting, and in Sect. 5 the connection between losses of internal tidal energy and vertical diffusivity is discussed.

\section{Area of investigation, field measurements and databases}

This section describes the area of investigation, the instrumental set-ups during the main recording period in 2009, as well as the environmental conditions during the period. Other data applied in this study and their sources are also discussed.

\subsection{The Oslofjord}

A typical fjord is often defined in textbooks (e.g. Syvitski et al., 1987) as an estuary modified by glaciers. A deep inner basin with an almost flat bottom is usually present. The Oslofjord on the other hand is part of a geological rift (Larsen, 2008), and this is evident in the bathymetry. The fjord can be divided into an outer and an inner part, where the latter is the subject of this study. The two parts are separated by the $12-\mathrm{km}$ long Drøbak Sound, with a shallow sill $(19.5 \mathrm{~m})$ at its northern end (Fig. 1a). The special characteristic of the Oslofjord compared to a typical fjord is its complicated topography, especially north of the Drøbak Sill (Fig. 1b). The Håøya Island divides the mouth of the inner fjord into two different channels: the eastern and western inlets. An artificial subsurface wall, the Drøbak Jetty, blocks the western inlet. The jetty has a depth of 1-2 m, except for two 6-m deep openings for smaller vessels. The crosssectional area over the Drøbak Jetty is only about $10 \%$ of the total cross section at the Drøbak Sill (Aas and Endresen, 1999; Table 3). Thus, the topography of the Drøbak Sill directs most of the baroclinic energy flux into the eastern channel, and accordingly we have focused our investigation on the flux in this channel. The eastern inlet, from the Drøbak Sill and $10 \mathrm{~km}$ northwards, has a complicated geometry, with two additional sills with depths of 47 and $62 \mathrm{~m}$ (Fig. 2), and several horizontal obstructions (Fig. 1b).

The inner fjord takes the shape of a horseshoe, and the two fjord basins, the Vestfjord and the Bunnefjord, are divided by the Nesodden Peninsula. Two sills of approximately $55 \mathrm{~m}$ 
Table 1. Instrumental set-up at the moorings. The parameters are $C=$ conductivity, $T=$ temperature, $P=$ pressure, $V=$ velocity.

\begin{tabular}{lllll}
\hline Location & Instrument & Depth(s) $[\mathrm{m}]$ & Recorded parameters & Sampling interval [min] \\
\hline S0 & Nortek Aqua. $600 \mathrm{kHz}$ & 27 & $V$ & 10 \\
S0 & Nortek Cont. 190 kHz & 89 & $V$ & 10 \\
S0 & TinyTag & $2 / 22 / 27 / 32 / 42 / 52 / 61 / 71 / 80$ & $T$ & 10 \\
S0 & YSI and Aanderaa Saiv & $4 / 17 / 37 / 90$ & $C T P$ & 10 \\
S1 & RDI 600 kHz & 24 & $V$ & 5 \\
S1 & SeaBird & 24 & $C T P$ & 5 \\
S2 & RDI 600 kHz ADCP & 23 & $V$ & 5 \\
S2 & SeaBird & $5 / 22 / 32 / 38 / 59 / 70 / 81$ & $C T P$ & 5 \\
S2 & SeaBird & $11 / 16 / 27 / 49$ & $C T$ & 5 \\
S2 & Nortek Cont. 190 kHz & 89 & $V$ & 10 \\
S5 & TinyTag & $2 / 9 / 13 / 18 / 23 / 33 / 38 / 43 / 48 / 58 / 63 / 68 / 73$ & $T$ & 10 \\
S5 & Aanderaa CT chain & $9 / 13 / 18 / 28 / 48$ & $C T$ & 10 \\
S5 & Aanderaa Saiv & 78 & $C T P$ & 10 \\
S5 & Nortek Cont. 190 kHz & 81 & $V$ & 10 \\
\hline
\end{tabular}

a)

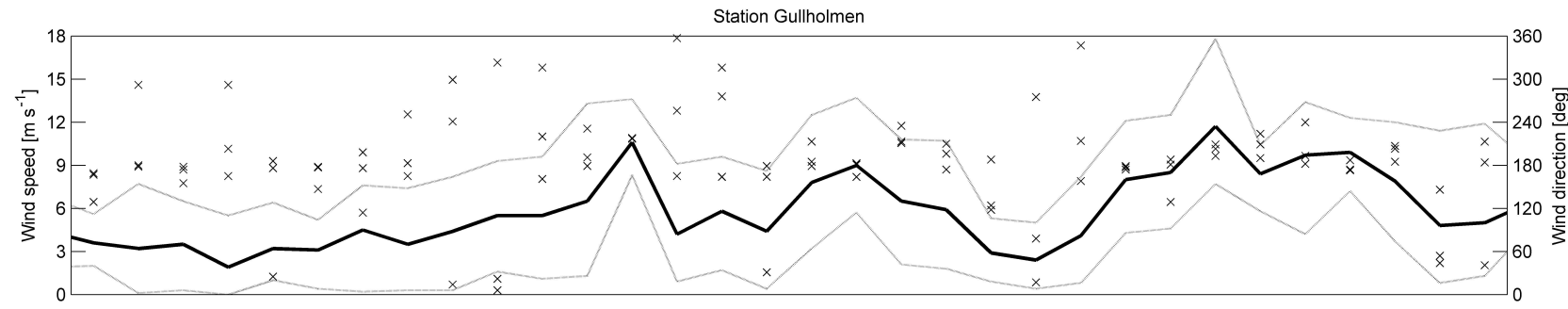

b)

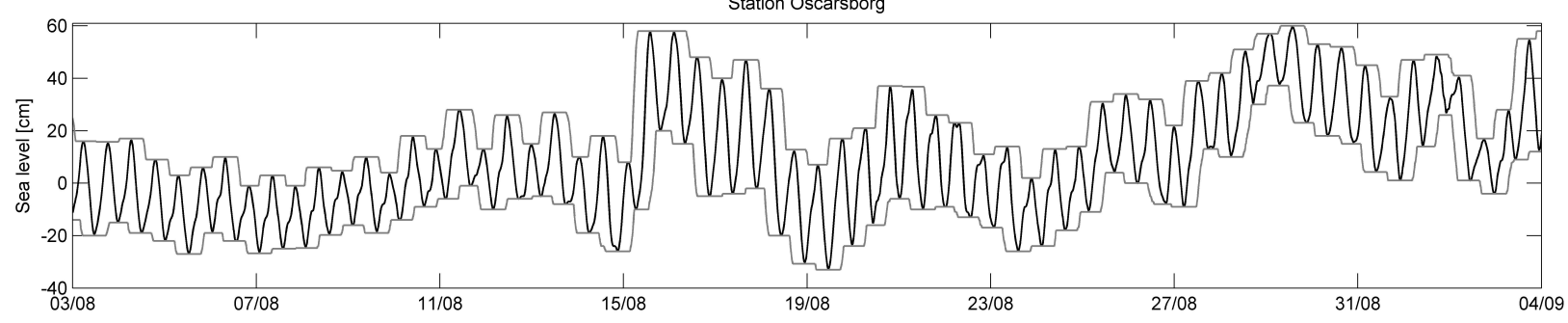

Fig. 3. (a) The wind conditions at the station Gullholmen approximately $26 \mathrm{~km}$ south of the Drøbak Sill. The thick black line represents the diurnal mean wind speed, the dotted lines the diurnal maxima and minima of the speed, and the crosses mark the wind directions. (b) Surface elevation measured at the station Oscarsborg close to S2 (black line). Grey lines indicate the 1 and 99 percentile elevations of the sea surface during a tidal cycle. These elevations are used in Eq. (5) to calculate the amplitude of the surface elevation.

depth, extending from the northern tip of Nesodden to the mainland on the other side, separate the two basins (Fig. 2).

The amplitude of the dominant tidal component $\mathrm{M}_{2}$ increases from $11.3 \mathrm{~cm}$ at Helgeroa (approximately $110 \mathrm{~km}$ south-east of Oslo) to $14.0 \mathrm{~cm}$ at Oslo (Fig. 1a). The phase lag between Oscarsborg (just north of the Drøbak Sill, close to S2, see Fig. 1a) and Oslo in the inner part of the fjord $(\sim 8 \mathrm{~min})$ is smaller than the corresponding lag of a free progressive shallow water wave $(\sim 18 \mathrm{~min})$. Thus, the tide behaves like a mixture of a standing and a progressive wave. During spring tides, the contributions from the harmonic overtides $\mathrm{MS}_{4}, \mathrm{M}_{4}$ and $2 \mathrm{SM}_{2}$ due to shallow water effects can be clearly seen in the tidal graphs, and in Sect. 3.2 it will be shown that these overtides are also present in the inter- nal tides. The average elevation of the sea surface inside the Drøbak Sill from low to high tide is $0.3 \mathrm{~m}$, and the corresponding average transport is $3 \times 10^{3} \mathrm{~m}^{3} \mathrm{~s}^{-1}$. The influence of weather on the surface elevation is frequently of the same order of magnitude as the tidal contribution. The estuarine circulation is relatively weak, since the fresh water supply to the inner fjord during the summer season is typically only $1 \%$ of the tidal transport. This implies that, although the tide is small, the tidal transports are still significant, which makes the fjord suitable for studies of tidal effects. 
(a)

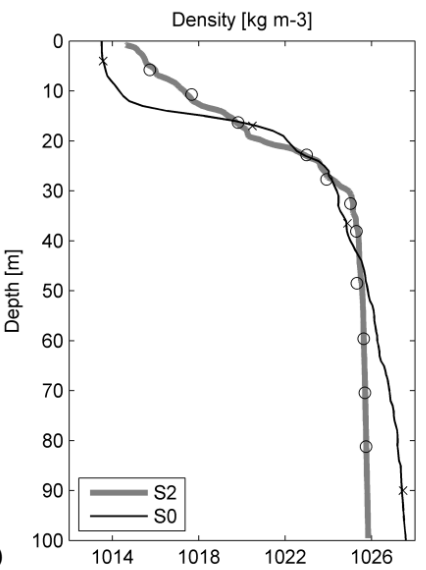

(b)

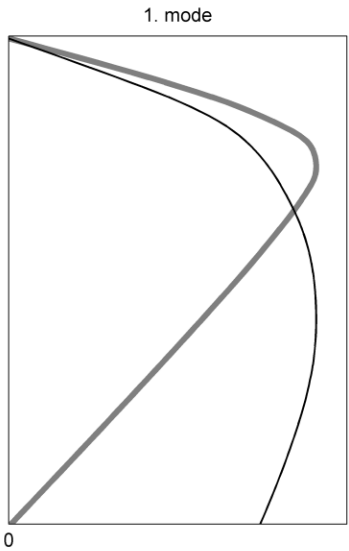

(c)

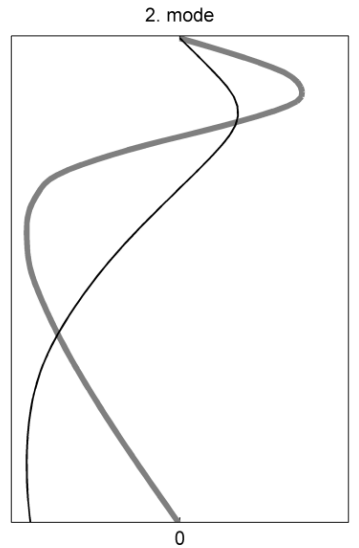

Fig. 4. (a) Comparison between density profiles measured with a CTD (lines) and moored instruments (symbols) at station S0 on 16 August 2009 and at station S2 on 18 August 2009. (b-c) The first and second mode of the vertical displacement at the two stations.

\subsection{Recordings and databases}

The main database consists of an extensive series of hydrographic data recorded between 3 August and 4 September 2009. To determine the energy flux in the internal waves propagating away from the Drøbak Sill, three moorings with CTD sensors were deployed close to moorings with acoustic current profilers at locations S0, S2 and S5 (Fig. 1). The instrumental set-up is summarized in Table 1. In addition, an acoustic current profiler with a CTD was deployed at the crest of the Drøbak Sill (S1). The deployment and recovery of the instruments were conducted by RV Trygve Braarud, and in general the data acquisition was successful. The wind conditions were relatively calm with mean wind speeds of $3-5 \mathrm{~m} \mathrm{~s}^{-1}$ during the first 10 days of the period, followed by three episodes of strong southerly winds with maximum wind speeds of more than $10 \mathrm{~m} \mathrm{~s}^{-1}$ on $15-16,20-23$, and 27 August-2 September, with calm conditions in between (Fig. 3a). The tidal amplitude of the surface elevation varied between 10 and $25 \mathrm{~cm}$, with a maximum in the middle of the period (Fig. 3b). Surface elevation and meteorological data have been obtained from the Norwegian Hydrographic Service and the Norwegian Meteorological Institute.

The temporal variation of the pressure recorded by the moored sensors had three contributions: the varying air pressure, the varying elevation of the sea surface created by tide and winds, and the shifting tilt of the mooring caused by the strong currents in the Drøbak Sound. The influences of varying air pressure and surface elevation were corrected for by data from the Meteorological Institute and the Hydrographic Service. The remaining pressure deviations from the nominal depth of the sensors were due to the tilts, and typical deviations during inflows were $0.4 \mathrm{~m}$, with spikes of up to $2.4 \mathrm{~m}$. The resulting errors have been corrected for by linear interpolations of the recorded quantities between the true depths.

Some CTD casts were taken close to the moorings during the recording period (Fig. 4). These continuous profiles were used to check the depths of the various sensors, as well as the accuracy of the depths of the density surfaces estimated by linear interpolation between these moored sensors. It was found that the error of the estimated depth for the density surfaces was less than one metre at depths with strong stratifications like the pycnocline (typically $15-25 \mathrm{~m}$ depth), while errors of up to $3 \mathrm{~m}$ occurred below the pycnocline. The method of linear interpolation between the moored sensors leads to mean errors in the vertical density gradient of $0.08 \mathrm{~kg} \mathrm{~m}^{-4}$. $80 \%$ of the errors were less than $0.1 \mathrm{~kg} \mathrm{~m}^{-4}$, while $4 \%$ of the errors were larger than $0.3 \mathrm{~kg} \mathrm{~m}^{-4}$, which is of the same order of magnitude as the gradient itself. The mean error is used in Sect. 4 to estimate the accuracy of the calculated energy densities.

Figure 5 presents the current conditions at stations $\mathrm{S} 0, \mathrm{~S} 1$, $\mathrm{S} 2$ and S5. At the last station, there was no instrument in the surface layer. Two periods are shown: from August 7th to 10th when the amplitude of the sea surface elevation was about $11 \mathrm{~cm}$ and from August 16th to 19th when the amplitude was $21 \mathrm{~cm}$. Temperature contours for $8.5,9,11,13,15$ and $17{ }^{\circ} \mathrm{C}$ are shown by black contour lines at stations S0, $\mathrm{S} 2$ and S5. As is also evident from Fig. 4, the density inside the Drøbak Sill is more homogeneous below the thermocline than outside the sill. At S0 the stratification is more influenced by the effects of the changing fresh water supply from outside the Drøbak Sound and the changing wind conditions. The data sets give us the opportunity to calculate the densities of potential energy from stratification data and kinetic energy from current data, independent of each other.

Hydrographic stations at different locations in the Oslofjord (S2, S3, S4, S5, S6, S7 and S8, Fig. 1a), sampled by NIVA since 1973 as part of a monitoring program, are used in Sect. 5.2 to determine the average vertical diffusivity in the different basins. 

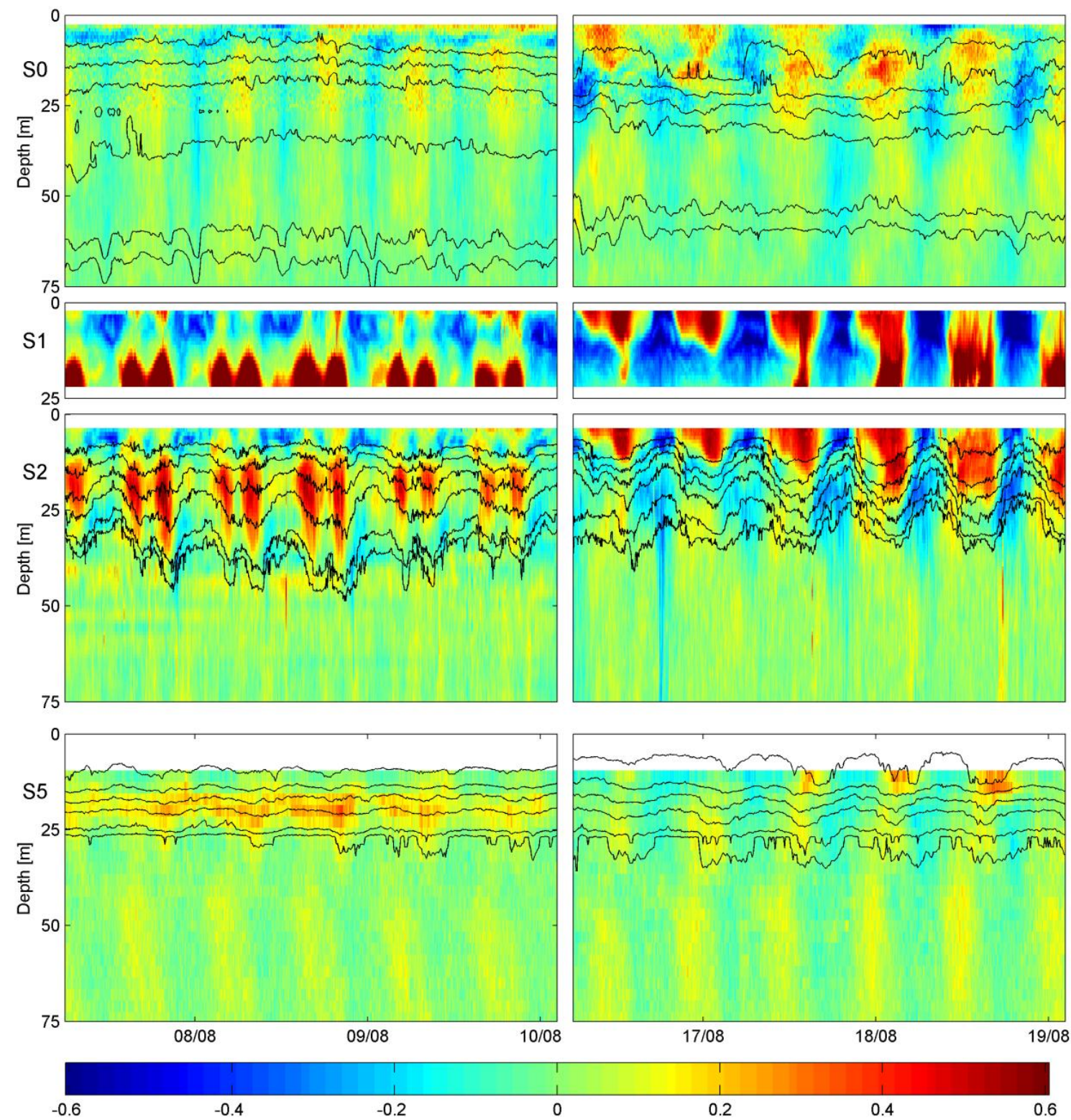

Fig. 5. The current speed along the fjord measured with acoustic current profilers at station S0 (Brenntangen), S1 (Drøbak sill), S2 (Kaholmen) and S5 (Søndre Langåra) is shown with a colour scale where red indicates current into and blue current out of the fjord. Temperatures of $8.5,9,11,13,15$ and $17^{\circ} \mathrm{C}$ increasing upwards are shown by black contour lines at stations S0, S2 and S5. The temperature has been interpolated linearly between the depths of the moored instruments. Two periods are shown: from 7 to 10 August when the sea surface amplitude was about $11 \mathrm{~cm}$ and from 16 to 19 August when the amplitude was $21 \mathrm{~cm}$.

Table 2. Characteristic parameters for the inner Oslofjord. The ranges are representative minimum and maximum values.

\begin{tabular}{lll}
\hline Parameter & Description & Range \\
\hline$A^{*}$ & Cross-sectional area of the fjord just outside the Drøbak sill & $(60-70) \times 10^{3} \mathrm{~m}^{2}$ \\
$Y$ & Horizontal area of the surface inside the Drøbak sill & $(188-192) \times 10^{6} \mathrm{~m}^{2}$ \\
$\omega$ & Angular frequency & $(1.40-1.45) \times 10^{-4} \mathrm{~s}^{-1}$ \\
$H_{1}$ & Thickness of the upper layer or sill depth & $(15-20) \mathrm{m}$ \\
$H_{2}$ & Thickness of the lower layer or height of the sill over the bottom & $(60-80) \mathrm{m}$ \\
$\Delta \rho$ & Difference between the mean densities above and below sill depth & $(5-15) \mathrm{kg} \mathrm{m}^{-3}$ \\
\hline
\end{tabular}



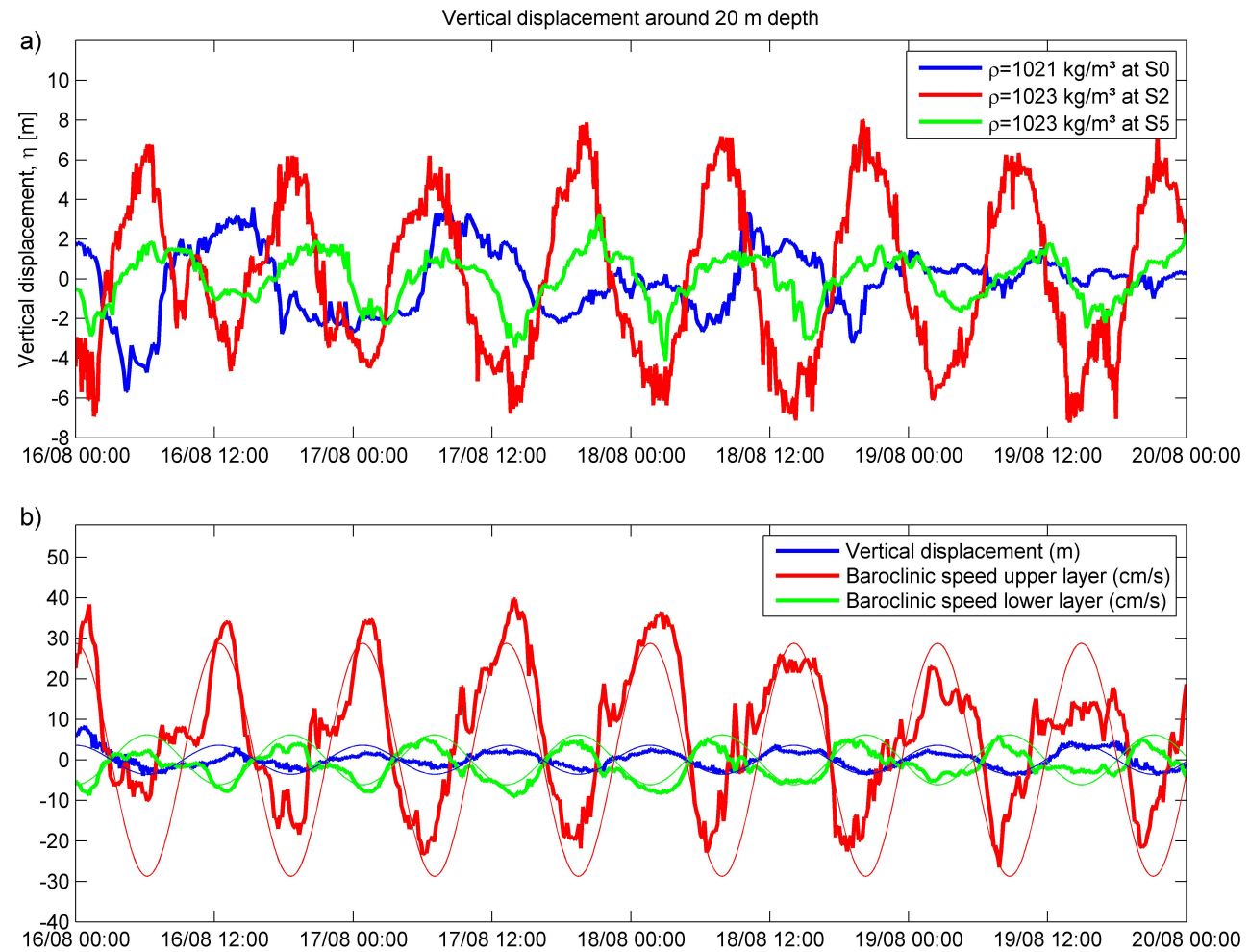

Fig. 6. (a) Vertical displacement of density surfaces at station S0, S2 and S5 at $20 \mathrm{~m}$ depth. (b) Vertical displacement and baroclinic speed in the upper and lower layer at station S2. Bold lines are the results from measurements, and thin lines are results from a two-layer model.

\section{Propagation of internal tides}

In this section the observations described in Sect. 2 are analysed to obtain the phase speeds, frequencies and amplitudes of the internal tides. The phase speed and frequency are important because they characterize the mode and the origin of the internal wave, and the amplitude is a measure of the wave energy.

\subsection{Phase speeds}

In a simple two-layer model, only one internal mode is possible, and the phase speed is

$c_{i}=\sqrt{g^{\prime} \frac{H_{1} H_{2}}{H_{1}+H_{2}}}$

where $g^{\prime}=g\left(\rho_{2}-\rho_{1}\right) / \rho_{2}$ is the reduced gravity, $\rho_{1}$ and $\rho_{2}$ are the densities of the upper and lower layer, respectively, and $H_{1}$ and $H_{2}$ are the undisturbed thicknesses of the two layers. Table 2 presents typical characteristics of the Oslofjord, and the ranges in the table reflect the uncertainties of the estimates. The thickness of the upper layer during the recording period corresponded to the sill depth. The values of $H_{1}$ and $H_{2}$ will depend on the interpretation of the topography, and similarly $g^{\prime}$ will depend on the value chosen for the density stratification. The range of $c_{i}$, based on Table 2 and Eq. (1), becomes $0.8-1.5 \mathrm{~m} \mathrm{~s}^{-1}$.

If we apply the observed continuous stratification instead of a two-layer model, more vertical modes of internal waves become possible (e.g. Gill, 1982), and the phase velocity for each mode can be calculated from vertical profiles of the Brunt-Väisälä frequency $N$, constructed from the recordings of density at the moored sensors. The results are sensitive to the choice of water depth, since deeper waters will produce higher phase speeds. In our calculations, a depth range of $80-100 \mathrm{~m}$ has been used (Fig. 2), and the ranges for the phase speeds of the first and second internal modes become $c_{1}=0.9-1.1 \mathrm{~m} \mathrm{~s}^{-1}$ and $c_{2}=0.4-0.5 \mathrm{~m} \mathrm{~s}^{-1}$ at station $\mathrm{S} 2$.

The phase speeds can also be determined directly from the observed phase shifts $\Delta t$ between the stations. We start by estimating the depth $z_{\rho}$ of the density surface $\rho$ by linear interpolation between the depths of the moored sensors. Vertical displacement profiles $\eta\left(t, \bar{z}_{\rho}\right)$ are constructed by subtracting the running mean depth $\bar{z}_{\rho}$ of this surface over two tidal cycles from $z_{\rho}$ :

$\eta\left(t, \bar{z}_{\rho}\right)=z_{\rho}-\bar{z}_{\rho}$.

This definition of $\eta$ ensures that $\bar{\eta}=0$, and the vertical displacement of density surfaces near the sill depth at $20 \mathrm{~m}$ depth is shown in Fig. 6a. The phase speed can be found from parallel time series of $\eta$ at two different stations in the 

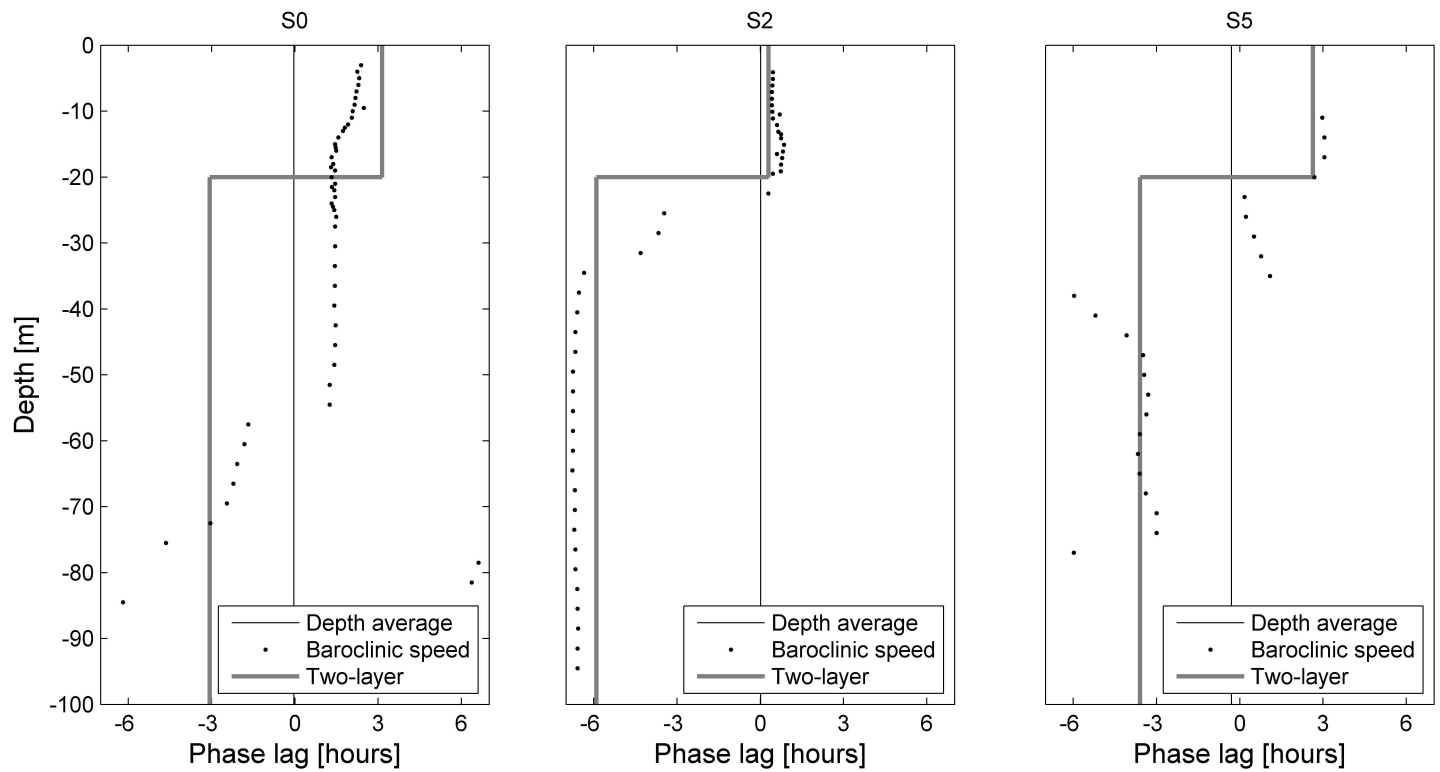

Fig. 7. Phase lag of the current measurements at stations S0 (left), S2 (middle) and S5 (right) relative to the depth-averaged current over the Drøbak Sill (station S1). The vertical solid line is the phase $(=0)$ of the depth-averaged current. The black dots are the phase lags of the measured baroclinic current (Eq. 4) as a function of depth, and the grey lines are the theoretical phase lags from two-layer theory (Eqs. 6-7 and Table 2.)

fjord. By shifting one of the time series an increasing interval $\Delta t$ in time until the highest correlation between the two series is found, the phase speed $c_{\rho}$ of the density surface $\rho$ can be determined from $\Delta t$ and the distance $\Delta L$ between the stations:

$c_{\rho}=\frac{\Delta L}{\Delta t}$

We call this the correlation method. The range of the phase speed $c_{\rho}$ between $\mathrm{S} 2$ and $\mathrm{S} 5$ found by determining $\Delta t$ from $\eta$ in Fig. 6a and using Eq. (3) is $1.2-1.5 \mathrm{~m} \mathrm{~s}^{-1}$. This agrees well with the range of $c_{i}$ found by the two-layer model and with $c_{1}$ obtained for the continuous stratification. It is noteworthy that $c_{\rho}$ is more than twice the speed $c_{2}$ found for the second internal mode. If we assume that the internal tide propagates as a progressive wave between $\mathrm{S} 2$ and $\mathrm{S} 5$, we can interpret the similarity between $c_{\rho}$ and $c_{1}$ as a confirmation of the dominance of the first mode at $20 \mathrm{~m}$ depth inside the sill. This does not mean that internal waves of higher modes are not present, but we will see in Sect. $4 \mathrm{~b}$ that the energy carried by the second mode is much less than the energy carried by the first mode, and that the energy of the second mode is lost between station S2 and S5.

According to linear theory (Stigebrandt, 1976), the vertical displacement at the sill should be in phase with the depthaveraged current over the sill. The depth-averaged current measured at $\mathrm{S} 1$ is therefore used as a reference. From the estimated phase shift between the vertical displacement at S0 shown in Fig. 6a and the barotropic current over the Drøbak Sill, an outward phase speed of $c_{\rho}=0.6 \mathrm{~m} \mathrm{~s}^{-1}$ can be found using Eq. (3). The phase speeds of the first and second mode calculated from the density profile at station S0 (Fig. 4a) are $c_{1}=1.2 \mathrm{~m} \mathrm{~s}^{-1}$ and $c_{2}=0.7 \mathrm{~m} \mathrm{~s}^{-1}$. The similarity between $c_{\rho}$ and $c_{2}$ might indicate that the second mode was dominant outside the Drøbak Sill during the period of investigation.

In order to estimate the energy transport, we need to know which way the internal tides propagate. The value of $c_{\rho}$ already found between S2 and S5 shows that the internal tide moves inwards from the Drøbak Sill. From Fig. 6a, it seems that the phases at both $\mathrm{S} 0$ and $\mathrm{S} 5$ are delayed compared to $\mathrm{S} 2$, indicating that the internal tides have originated at the sill. The figure also shows that the oscillations at S0 are irregular, which may be a result of interaction with internal waves that have originated outside the Drøbak Sound.

An internal wave sets up a horizontal baroclinic speed $u^{\prime}$, defined as

$u^{\prime}=u-\langle u\rangle_{H}$

where $u$ is the current speed in the same direction as the propagation of the internal wave, and $\langle u\rangle_{H}$ is the barotropic part of the current speed, calculated as the depth-average of the recorded current profile.

Stigebrandt (1976) solved the linearized shallow-water equations with no rotation for the two-layer case, while applying a local boundary condition at the sill that cancelled the barotropic current in the lower layer. The solution contains a vertical displacement $\eta$ of the interface between the two layers that propagates as an internal wave in both directions away from the sill. The expressions for the vertical displacement $\eta$ and the baroclinic currents $u_{1}^{\prime}$ and $u_{2}^{\prime}$ in the 
two layers inside the sill, with the $x$-axis pointing into the fjord and the sill located at $x=0$, are

$\eta=a_{\eta} \sin (\omega t-k x)$

$u_{1}^{\prime}=a_{\eta} \frac{c_{i}}{H_{1}} \sin (\omega t-k x)$

$u_{2}^{\prime}=-a_{\eta} \frac{c_{i}}{H_{2}} \sin (\omega t-k x)$

Here $k=\omega / c_{i}$ is the horizontal wave number, and $\omega$ is the angular frequency of the semidiurnal tide. The amplitude of the vertical displacement of the interface is $a_{\eta}=U^{*} H_{2} / c_{i}$, where $U^{*}=\omega a_{\zeta} Y / A^{*}$ has the units of a velocity. Here $Y$ denotes the surface area of the entire fjord inside the sill, $A^{*}$ is the cross-sectional area of the channel just outside the sill and $a_{\zeta}$ is the amplitude of the surface elevation. The baroclinic currents of the internal wave in the two layers have a phase difference of $180^{\circ}$ relative to each other. The vertical integral of the baroclinic horizontal velocities from bottom to top becomes zero, implying that only the barotropic current contributes to the depth-averaged current speed.

The quantities $\eta, u_{1}^{\prime}$ and $u_{2}^{\prime}$ have been calculated by the expressions Eqs. (5)-(7) with values from Table 2, and the results are presented in Fig. $6 \mathrm{~b}$ together with the observed vertical displacement of the interface and the depth-averaged baroclinic currents above and below $15 \mathrm{~m}$ at station S2. The figure demonstrates there is a good agreement between the measurements and the theoretical two-layer results. The observed baroclinic speed above the pycnocline is in phase with the vertical displacement, indicating that the internal tide propagates as a first-mode progressive wave at station S2. On the other hand, the result $c_{\rho}>c_{1}$ indicates that some of the energy in the internal wave is reflected, since $\Delta t$ in Eq. (3) is reduced when an outward reflected wave is added to the inward progressive wave. It must be remarked that these results represent a spring tide situation where the surface amplitude $a_{\zeta}$ is about $20 \mathrm{~cm}$ (Fig. 3b), and that the agreement is less clear when the tidal forcing is weaker.

Figure 7 presents the phase lag of the baroclinic current estimated from the recordings of the acoustic current profilers using Eq.(4) at stations S0, S2 and S5 relative to the phase of the barotropic current over the sill at S1. A positive phase lag means that the phase is smaller than the phase of the barotropic wave at S1. The phase lag according to twolayer theory (Stigebrandt, 1976) for a $\mathrm{M}_{2}$ wave with $c_{i}$ set to $1.15 \mathrm{~m} \mathrm{~s}^{-1}$ (the middle point of the range in Table 2) is plotted as grey lines in Fig. 7. The observed baroclinic velocity inside the sill above $20 \mathrm{~m}$ and below $40 \mathrm{~m}$ agrees well with the theoretical baroclinic wave of the two-layer model propagating into the fjord. Yet the phase lag between 20 and $40 \mathrm{~m}$ depth is smaller than expected at both station S2 and S5 (Fig. 7). It is thus possible that the two-layer model is too simple to reproduce all aspects of the phase lag. It is also possible that the topography north of the Drøbak Sill may play a role at S2 and S5, either by creating additional internal waves or reflecting internal waves generated at the
Drøbak Sill. At S0 the two-layer model with the interface at sill depth fails completely to predict the observed phase lags. Reasons for this could be (i) that the first mode has a maximum at 50-60 m depth at S0 (Fig. 4b), and vertical oscillations at sill depth is associated with higher modes, as the calculated phase speeds at S0 indicate, or (ii) that internal waves generated in the outer fjord may dominate the baroclinic current field in the Drøbak Sound.

\subsection{Amplitudes}

During the recording period of one month, the tidal amplitudes of the surface elevation and the internal wave will vary due to the spring-neap effect, and in order to study the instantaneous amplitude we use what can be called the envelope method. Let $h(t)$ be a time series of the vertical elevation of a density surface. Further, let $h_{1}$ and $h_{99}$ be the 1 and 99 percentiles of the time series over the tidal period $T=12.5 \mathrm{~h}$ from $t-T / 2$ to $t+T / 2$. These two new time series are assumed to represent the upper and lower rims of the envelope of the time series $h(t)$. The percentiles are used instead of maximum and minimum values in order to remove spikes. The amplitude $a_{h}$ of $h$ can then be defined as

$a_{h}(t)=\frac{1}{2}\left(h_{99}(t)-h_{1}(t)\right)$

The amplitudes of the vertical displacement, calculated with the envelope method as a function of depth at station S2 and S5, are plotted in Fig. 8a. The mean value \pm the standard deviation of the amplitude between 15 and $25 \mathrm{~m}$ depth is $5.7 \pm 1.0 \mathrm{~m}$ and $1.7 \pm 0.4 \mathrm{~m}$ at stations $\mathrm{S} 2$ and $\mathrm{S} 5$ respectively, while the maximum amplitudes $(7.4 \pm 1.3 \mathrm{~m}$ at $\mathrm{S} 2$ and $3.5 \pm 1.0$ at S5) are found around a depth of $40 \mathrm{~m}$ at both stations. When the vertical displacement at S2 is fitted to the normal modes shown in Fig. 4, it is found that the amplitude around $20 \mathrm{~m}$ depth is associated with the first mode while the amplitude around $40 \mathrm{~m}$ depth is associated with higher modes. The amplitude of the internal waves between 15 and $25 \mathrm{~m}$ depth correlates with the amplitude of the surface elevation. This is not the case deeper down in the water column, and at $40 \mathrm{~m}$ depth there is no apparent correlation between amplitudes of the internal wave and the sea surface, as demonstrated by Fig. 8b. On the other hand, at this depth at station S2 there is a correlation (not shown here) of 0.62 between the amplitude of the vertical displacement and $|\partial \rho / \partial z|$, indicating that greater amplitudes appear when the stratification is stronger. There is no such correlation at $20 \mathrm{~m}$ depth.

It is worth noting from Fig. 5 that the amplitudes of the displacement of temperature surfaces at station S2 at $40 \mathrm{~m}$ depth seem to be greatest in the first part of the recording period when the amplitude of the sea surface is smallest, and that this can be associated with strong inflows in the form of jet-like currents around sill depth. These amplitudes are then not a linear response to the tidal currents, but to jets 
a)

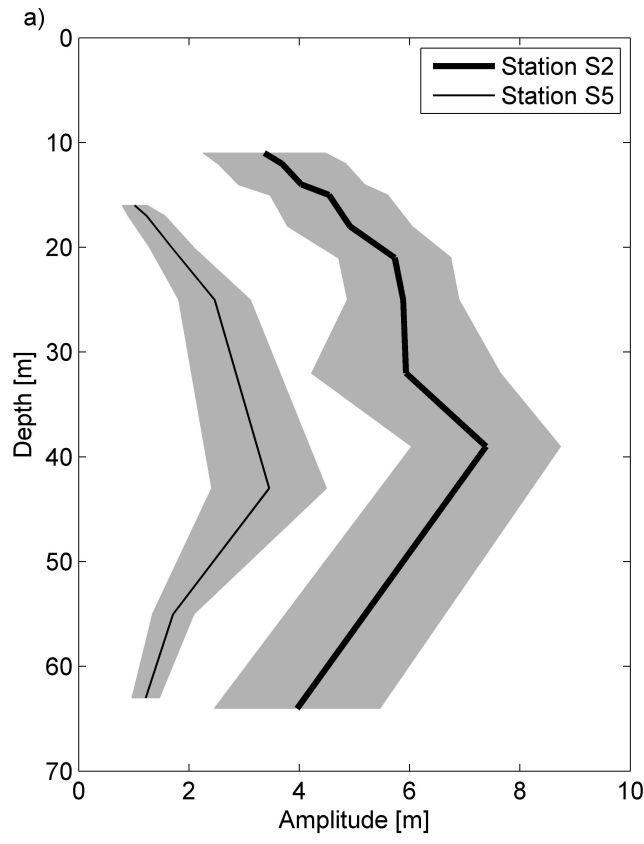

b)

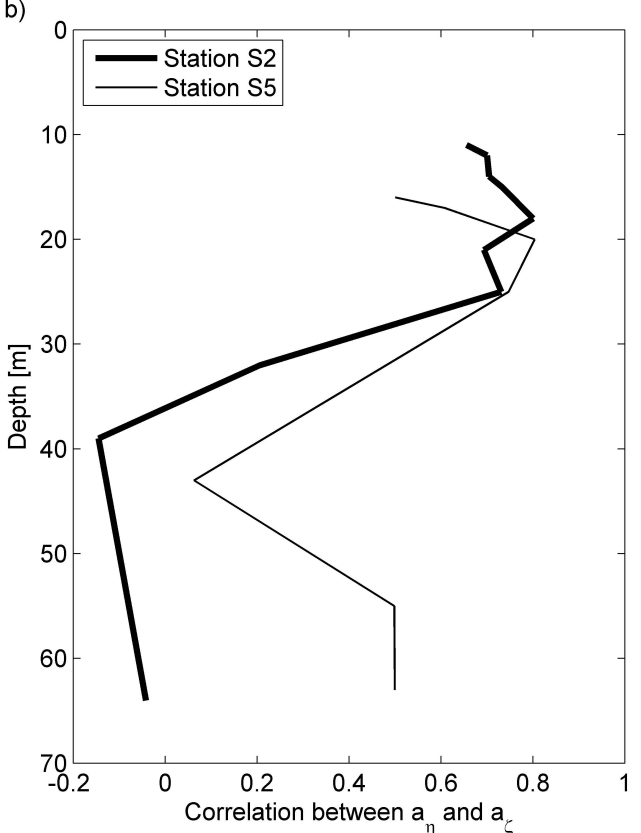

Fig. 8. (a) Amplitude of the vertical displacements of different density surfaces as a function of depth at station S2 (thick lines) and station S5 (thin lines). The mean amplitude is plotted with lines, and grey shaded areas indicate the mean amplitude \pm one standard deviation. (b) Correlation coefficient between the amplitude of the surface elevation and the amplitude of the vertical displacement of different density surfaces as a function of depth for station S2 (thick line) and station S5 (thin line).

that are able to depress the density surfaces below sill depth downwards.

By applying the definition Eq. (8) to the surface elevation $\zeta$ and the internal vertical displacement $\eta$, we obtain an ensemble of data for the respective amplitudes $a_{\zeta}$ and $a_{\eta}$ that can be used to estimate the amplitude ratio $\gamma$ defined as

$\gamma=\frac{a_{\eta}}{a_{\zeta}}$

We will focus on $a_{\eta}$ around the pycnocline since this layer has the strongest correlation to the surface tides (Fig. 8b), and because this layer is also the most energetic as more energy is needed to displace water parcels in strong stratifications. Fig. 9 presents the amplitudes of the displacements of the $1023 \mathrm{~kg} \mathrm{~m}^{-3}$ density surface at station S2 and S5 plotted as a function of the sea surface amplitude, where the values of $a_{\zeta}$ and $a_{\eta}$ have been obtained from the observed surface elevation and vertical displacement by the envelope method (Eq. 8). Estimates of the ratio $\gamma$ (Eq. 9) based on these amplitudes vary in the range $38.4 \pm 5.5$ at station $\mathrm{S} 2$ where the correlation coefficient between $a_{\zeta}$ and $a_{\eta}$ is 0.69 , and in the range $11.2 \pm 1.6$ at station S5 where the coefficient is 0.80 . This means that the amplitude $a_{\eta}$ at station S5 is reduced to $20-40 \%$ of the same amplitude at station S2.

The ratio (Eq. 9), based on Stigebrandt's solution (Eqs. 57), becomes

$\gamma=\frac{H_{2} Y}{A^{*}} \frac{\omega}{c_{i}}$

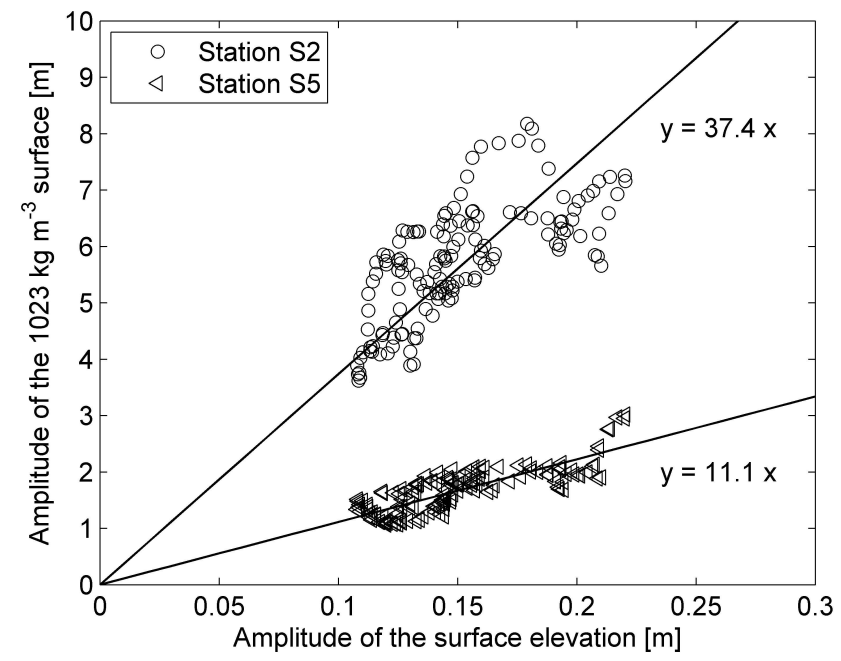

Fig. 9. The amplitude of the displacement of the $1023 \mathrm{~kg} \mathrm{~m}^{-3}$ density surface at station S2 (circles) and S5 (triangles) plotted as a function of the amplitude of the surface elevation. The lines are least square fits intercepting the origin.

The ratio $\gamma$ has a constant part $H_{2} Y / A^{*}$ depending on the fjord geometry and a varying part $\omega / c_{i}$ depending on the driving force and the stratification. Equation (10) is very useful because it predicts how much energy is likely to be present in the form of internal tides in a sill fjord, prior to any local measurements of surface elevations and 


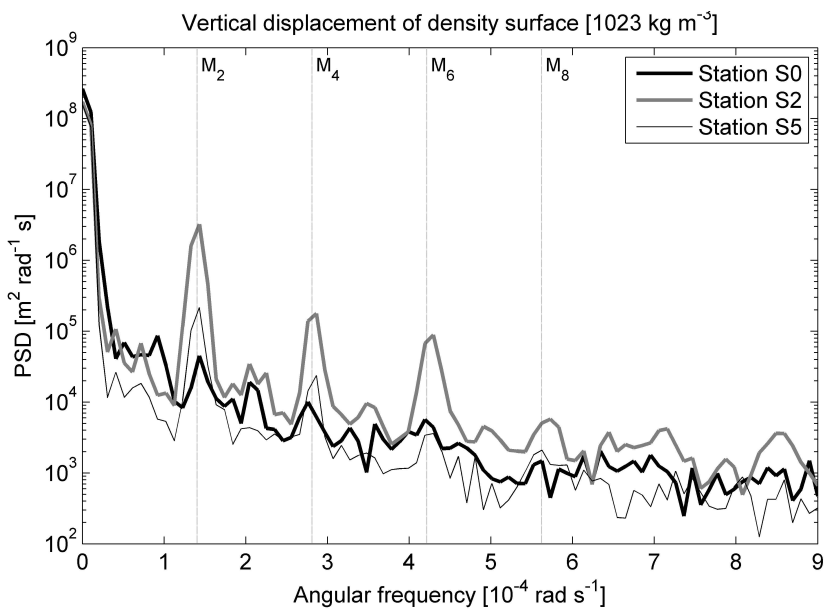

Fig. 10. Power spectral density (PSD) for the $1023 \mathrm{~kg} \mathrm{~m}^{-3}$ density surface at stations S0, S2 and S5 as a function of the angular frequency. According to the harmonic analysis, the PSDs of $\mathrm{M}_{2}, \mathrm{M}_{4}$ and $\mathrm{M}_{6}$ are significant (95\%) at both S2 and S5. At S0 only the PSDs of $\mathrm{M}_{2}$ and $\mathrm{M}_{3}$ are significant.

internal displacements. The insertion of values from Table 2 in Eq. (10) results in estimates of $\gamma$ in the range $31 \pm 15$. This compares well with the range for $\gamma$ found at S2 from Eq. (9). The damping of the vertical displacement further into the fjord, as observed at station S5, was explained by Stigebrandt (1979) as a result of the widening of the fjord. But as we will see in Sect. 5, this effect does not explain all of the damping, and some of the baroclinic energy must be lost between S2 and S5.

The frequency spectrum obtained by the temporal resolution of 5 and $10 \mathrm{~min}$ and the fast Fourier transform for the $1023 \mathrm{~kg} \mathrm{~m}^{-3}$ density surface at station $\mathrm{S} 2$ at around $20 \mathrm{~m}$ depth (Fig. 10) exhibits energy peaks near the semidiurnal frequency $\mathrm{M}_{2}$, as well as at the associated harmonic overtides $\mathrm{M}_{4}, \mathrm{M}_{6}$ and $\mathrm{M}_{8}$. For simplicity, Fig. 10 attributes all of the tidal energy to these lunar constituents. The figure displays the same peaks at station S5, but not as clearly. At station S0 outside the sill, these peaks are even less significant.

The damping observed at $\mathrm{S} 0$ of the internal tides propagating out of the fjord (Fig. 10) cannot be explained by a widening of the fjord since this part of the fjord south of the sill is almost straight. The most striking difference between the fjord outside and inside the Drøbak Sill is the stronger stratification below sill depth at the outside. It is possible that this contributes to a stronger dampening of the wave in the lower layer.

Examination of echo sounder images from a station in the Bunnefjord close to S8 during the winter of 2009/2010 reveals no signs of first-mode internal waves with semidiurnal frequency, even though oscillations with longer and irregular periods are found. (Details of the applied method of analysis have been presented by Kaartvedt et al., 2009).

\section{Energy density and energy transport in internal tides}

In this section, we will use the phase speeds and amplitudes found in the preceding section to calculate the energy density of the internal tides and the corresponding energy flux.

\subsection{Calculation of energy density}

The energy densities induced by internal tides can be found from the vertical density profiles. If $\eta\left(t, \bar{z}_{\rho}\right)$ is the displacement of a fluid element from its equilibrium position $\bar{z}_{\rho}$, obtained from Eq. (2), the potential energy per volume unit (in $\mathrm{J} \mathrm{m}^{-3}$ ) caused by this displacement can be estimated by the expression (e.g. Gill, 1982 or Cottier et al., 2004)

$E_{p}\left(t, \bar{z}_{\rho}\right)=-\frac{1}{2} g \overline{\eta^{2}} \frac{d \bar{\rho}}{d z}=-\frac{1}{4} g a_{\eta}^{2} \frac{d \bar{\rho}}{d z}$

The harmonic coefficients presented by the Norwegian Hydrographic Service show that the semidiurnal constituents $\mathrm{M}_{2}, \mathrm{~S}_{2}$ and $\mathrm{N}_{2}$ will dominate the barotropic tide, but the amplitude of the diurnal $\mathrm{O}_{1}$ is still about $15 \%$ of $\mathrm{M}_{2}$ in the Oslofjord, and an averaging period of $25 \mathrm{~h}$ has therefore been employed to obtain the undisturbed density profile $\bar{\rho}(z)$. This means that Eq. (11) can be regarded as the potential energy density for the internal tides averaged over the tidal period. In the last term, it has been assumed that the wave has a sinusoidal shape.

The kinetic energy density of the internal tide averaged over the tidal period can be written as

$E_{k}(t, z)=\frac{1}{2} \overline{\rho u^{\prime 2}}$

where the baroclinic current speed $u^{\prime}$ is defined by Eq. (4).

In Stigebrandt's two-layer model (1976), the depthaveraged potential energy density caused by the perturbation of the internal wave is, when averaged over a tidal period,

$\left\langle E_{p}\right\rangle_{H}=\frac{1}{2} g \overline{\eta^{2}} \frac{\left(\rho_{2}-\rho_{1}\right)}{H}=\frac{\gamma^{2} a_{\zeta}^{2}}{4} \frac{g\left(\rho_{2}-\rho_{1}\right)}{H}=\frac{\gamma^{2} a_{\zeta}^{2} c_{i}^{2} \rho_{2}}{4 H_{1} H_{2}}$.

\langle\rangle$_{H}$ is the average over the water depth $H$ and $\overline{()}$ is the average over the tidal period $T$. The equality $\bar{\eta}=0$ has been used. The corresponding depth and time-averaged kinetic energy density becomes

$\left\langle E_{k}\right\rangle_{H}=\overline{\frac{1}{H} \int_{-H}^{\zeta} \frac{1}{2} \rho u^{\prime 2} d z}=\frac{\gamma^{2} a_{\zeta}^{2} c_{i}^{2}}{4 H}\left(\frac{\rho_{1}}{H_{1}}+\frac{\rho_{2}}{H_{2}}\right) \approx \frac{\gamma^{2} a_{\zeta}^{2} c_{i}^{2} \rho_{2}}{4 H_{1} H_{2}}$

In the last term of Eq. (14), the approximation $\rho_{1} / \rho_{2} \approx 1$ has been used, resulting in a kinetic energy density equal to Eq. (13). By taking the sum of Eqs. (13) and (14), we obtain the same total energy density as used by Stigebrandt. We see from Eqs. (13) and (14) that, in the special case of two-layer stratification, the ratio between the potential and kinetic energy densities is 1 . 

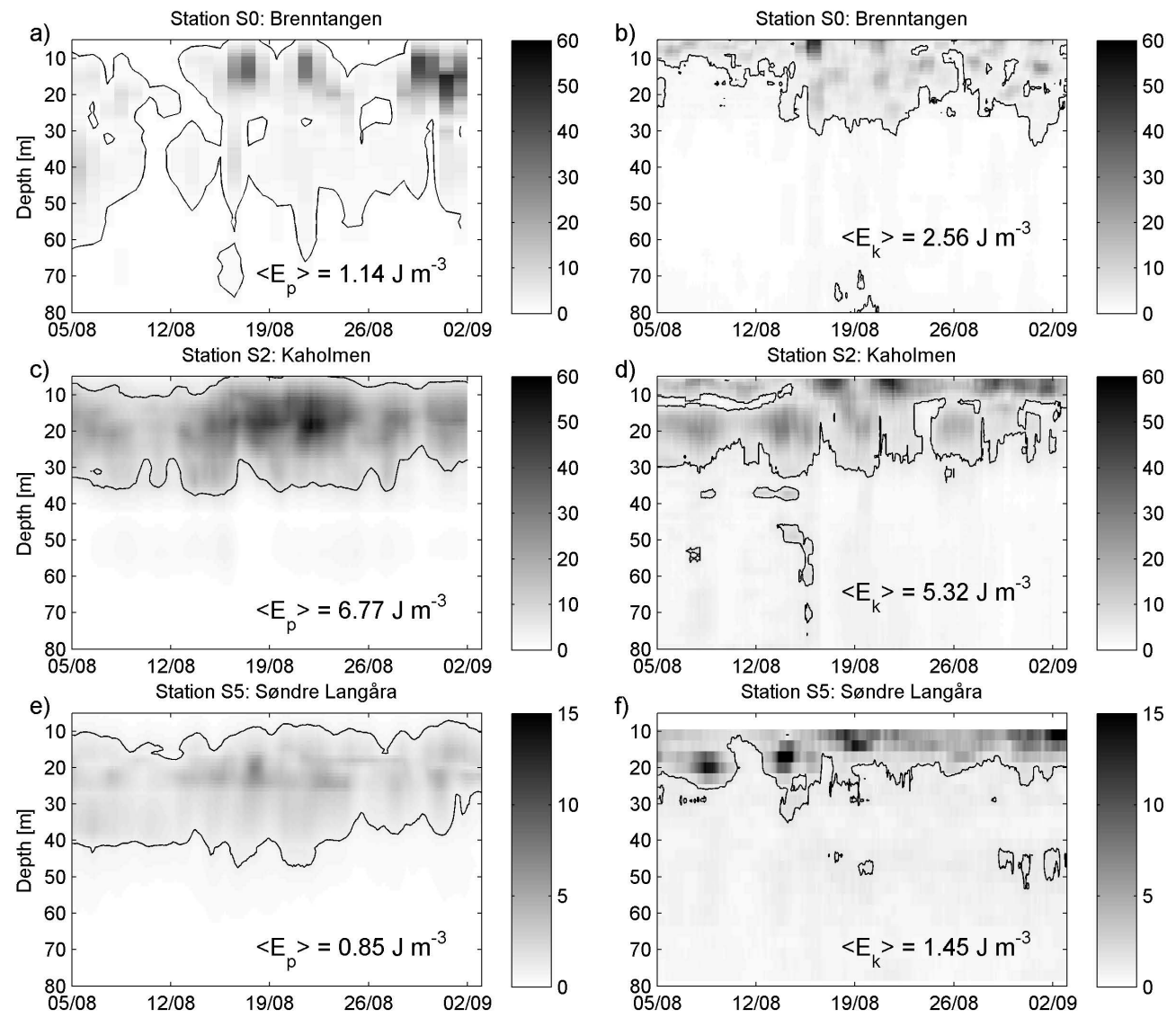

Fig. 11. Baroclinic energy densities are shown with a grey scale where darker shades indicate higher values in unit $\mathrm{J} \mathrm{m}^{-3}$ for stations $\mathrm{S} 0$ $\left((\mathbf{a})\right.$ and (b)), S2 ((c) and (d)) and S5 ((e) and (f)). Potential energy density $E_{p}$ (Eq. 11) is shown to the left and kinetic energy density $E_{k}$ (Eq. 12) to the right. A sliding mean with period of 25 hours is applied to cancel out the tidal oscillations. The average of the energy densities $\left\langle E_{p}\right\rangle$ and $\left\langle E_{k}\right\rangle$ for the whole period and for all depths is indicated with a number, and a contour line with this value is drawn in each plot.

Energy densities have been calculated from observed density profiles and current measurements using Eqs. (11) and (12) for the stations S0, S2 and S5, and the results are presented in Fig. 11. At all stations, the energy density is highest in the upper layer. $E_{p}$ has a maximum around the pycnocline. S2 is the most energetic station, with a total energy density more than 5 times higher than at the other stations.

At $\mathrm{S} 0$ vertical displacement profiles were constructed from temperature rather than density since there was a satisfactory number of sensors for temperature at this station, but not for conductivity. Outside the sill, the mean value of the ratio $\left\langle E_{p}\right\rangle_{H} /\left\langle E_{k}\right\rangle_{H} \pm$ the standard deviation for the whole period is $0.4 \pm 0.3$. Inside the sill, the ratio $\left\langle E_{p}\right\rangle_{H} /\left\langle E_{k}\right\rangle_{H}$ is closer to 1. Figure 12a demonstrates that, at $\mathrm{S} 2,\left\langle E_{p}\right\rangle_{H}$ and $\left\langle E_{k}\right\rangle_{H}$ are almost of the same value until 15 August, but after that date $\left\langle E_{p}\right\rangle_{H}$ is higher. The mean value of the ratio for the whole period is $1.3 \pm 0.4$. At $S 5,\left\langle E_{p}\right\rangle_{H}$ is a little lower than $\left\langle E_{k}\right\rangle_{H}$ most of the time, with $\left\langle E_{p}\right\rangle_{H} /\left\langle E_{k}\right\rangle_{H}=0.6 \pm 0.2$.

The errors in the estimates of the density gradients $\left(0.08 \mathrm{~kg} \mathrm{~m}^{-4}\right)$ and the depths of the density surfaces $(1 \mathrm{~m})$ mentioned in Sect. 2 imply that the errors of the calculated potential energy densities are up to $50 \%$. If the error of the current measurement is $1 \mathrm{~cm} \mathrm{~s}^{-1}$ for a typical current speed of $20 \mathrm{~cm} \mathrm{~s}^{-1}$, the error of the calculated kinetic energy density is only $10 \%$, but a more serious source of error is the possibility that the baroclinic current calculated from Eq. (4) may have other causes than just the internal tides. $E_{k}$ has high values near the surface at station S0 and S2 at approximately the same times as when high wind speeds are observed (Fig. 3a). At S5 there are no current measurements near the surface. The results in Fig. 11 must then be interpreted with caution.

\subsection{Estimated energy fluxes}

The energy flux associated with internal waves through a cross section $A$ can be written (in units of $\mathrm{W}$ ) as

$F_{i}^{p}=A\left\langle\overline{p^{\prime} u^{\prime}}\right\rangle_{A}$

where $u^{\prime}$ is the baroclinic speed and $p^{\prime}$ is the perturbation pressure caused by the internal waves. The subscript $i$ indicates the station index and the superscript indicates 
Table 3. Selected cross-sectional areas in the inner Oslofjord (see Fig. 13).

\begin{tabular}{|c|c|c|c|c|}
\hline Cross section & Description & Max depth (m) & Width (m) & Area $\left(\mathrm{m}^{2}\right)$ \\
\hline $\mathrm{A}_{1 E}$ & Over the eastern part of the Drøbak Sill & 20 & 800 & 9500 \\
\hline $\mathrm{A}_{1 W}$ & Over the western part of the Drøbak Sill & 6 & 700 & 1000 \\
\hline $\mathrm{A}_{2}$ & Across the eastern channel at station $\mathrm{S} 2$ & 100 & 500 & 35400 \\
\hline $\mathrm{A}_{3 E}$ & $\begin{array}{l}\text { Across the eastern channel on } \\
\text { the east side of the Aspond Island }\end{array}$ & 87 & 550 & 27800 \\
\hline $\mathrm{A}_{3 W}$ & $\begin{array}{l}\text { Across the eastern channel on the } \\
\text { west side of the Aspond Island }\end{array}$ & 86 & 450 & 16000 \\
\hline $\mathrm{A}_{4}$ & Division between Basin 4 and 5 & 72 & 1900 & 46100 \\
\hline$A_{5}$ & $\begin{array}{l}\text { Across the eastern channel at station S5 between } \\
\text { the mainland and the Søndre Langåra Island }\end{array}$ & 160 & 900 & 59700 \\
\hline
\end{tabular}

the method used, in this case $p$ for the perturbation pressure method. This method is used by for instance Kunze et al. (2002) where the pressure anomaly $p^{\prime}$ induced by the internal tide is calculated by assuming hydrostatic pressure:

$p^{\prime}(z)=\int_{z}^{0} g \rho^{\prime}\left(z^{\prime}\right) d z^{\prime}-\left\langle\int_{z}^{0} g \rho^{\prime}\left(z^{\prime}\right) d z^{\prime}\right\rangle_{H}$

and the perturbation density $\rho^{\prime}$ is obtained from

$\rho^{\prime} \approx \eta \frac{d \bar{\rho}}{d z}$

It follows from Gill and Clarke (1974) that $\left\langle p^{\prime}\right\rangle_{H}=0$, and this determines the integration constant (second term on the right hand side of Eq. (16)). Gill and Clarke assumed a flat bottom in order to separate the horizontal and vertical dependencies of the variables. The flat bottom is clearly not the case in the Oslofjord, but compared to the wavelength of the internal tides, the bathymetry might be regarded as bottom roughness on an otherwise flat bottom.

\langle\rangle$_{A}$ indicates an average over a cross section area. The cross section areas of the fjord at stations S2 and S5 are listed in Table 3 and shown in Fig. 13. Since only one station is available in each cross section, an uncertainty is introduced due to the uncertainty of the representativity of this station for the whole cross section. However, the width of the eastern channel is much less than the internal mode-1 Rossby radius ( 6 to $10 \mathrm{~km}$ ), and consequently it has been assumed as a first approximation that $p^{\prime}$ and $E_{p}$ at each depth represent the whole width of the channel. The depth-average from the surface and down to a bottom depth approximately equal to the mean bottom depth across the channel has been chosen to represent the mean value over the whole cross section. By choosing different bottom depths for the depth-average and comparing the results, an uncertainty of $\pm 15 \%$ has been found.

The quantities $u^{\prime}$ and $p^{\prime}$ can be separated into time $\left(U_{n}\right.$, $\left.P_{n}\right)$ and depth $\left(\tilde{u}_{n}, \tilde{p}_{n}\right)$ dependent parts. The vertical structure of each internal mode $n\left(\tilde{u}_{n}, \tilde{p}_{n}\right)$ is calculated from the mean stratification (e.g. Gill, 1982). $U_{n}$ and $P_{n}$ are found by fitting the baroclinic velocity (Eq. 4) and pressure (Eq. 16) respectively. The energy flux can then be obtained from

$F_{i}^{m}=A \sum_{n=1}^{\infty} P_{n}(t) U_{n}(t) \tilde{u}_{n}(z) \tilde{p}_{n}(z)$

where the superscript $m$ stands for the normal mode method. Thus, this method gives the possibility to separate the energy flux into different normal modes. At S2 $13 \%$ of the energy flux is in the second mode. At S5 nearly $100 \%$ of the energy is in the first mode. This means that all of the higher mode energy flux is dissipated between stations S2 and S5.

An internal wave with a semidiurnal period will have a wavelength of more than $40 \mathrm{~km}$ for a phase speed of $1 \mathrm{~m} \mathrm{~s}^{-1}$. This type of internal wave can be regarded as a long interfacial wave if it occurs in a layer of strong stratification, and its group velocity $c_{g}$ is therefore approximately the same as the phase velocity. The amount of energy transported by the internal wave away from its area of origin through a vertical section $A$ across the fjord can then be written as

$F_{i}^{d}=A\left\langle c_{g}\left(E_{p}+E_{k}\right)\right\rangle_{A}$

where the superscript $d$ designates the energy density method.

The energy densities in Eq. (19) can be calculated from the continuous stratification (Eqs. (11)-(12)) or from the two-layer model (Eqs. (13)-(14)). By inserting the two-layer energy densities into Eq. (19), the energy flux becomes

$F_{i}^{\mathrm{two}}=\frac{A \rho_{2}}{2 H_{1} H_{2}} a_{\eta}^{2} c_{g}^{3}$

where the superscript $t w o$ refers to the two-layer model.

Figure $12 \mathrm{~b}$ and $\mathrm{c}$ present an overview of the energy fluxes at station S2 and S5 obtained by using Eqs. (18)-(20). The perturbation pressure method (Eq. 15) is only applied at station S2 (not shown), and the results agree well with the results from Eq. (18). The mean values during the whole measurement period are summed up in Table 4. 

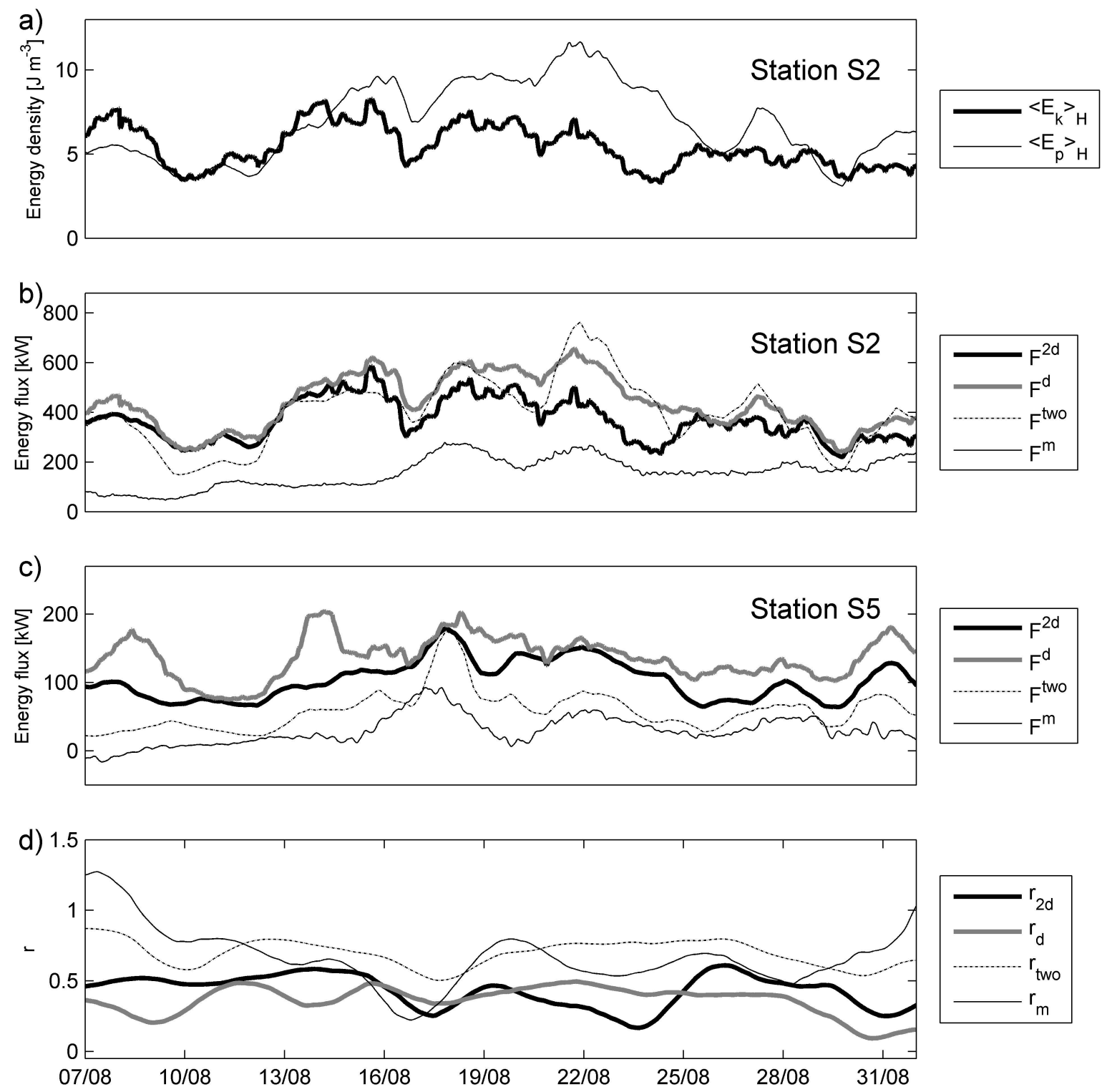

Fig. 12. (a) The depth-averaged perturbation energy densities $\left\langle E_{p}\right\rangle$ and $\left\langle E_{k}\right\rangle$ at station $\mathrm{S} 2$. (b)-(c) The energy flux $F$ calculated with different methods at stations S2 and S5. (d) The relative loss $r$ of baroclinic energy flux in the area between stations S2 and S5 calculated from Eqs. (21) and (22) with $f=1$. At the start of the period, there is a negative energy flux at station S5 calculated with the normal mode method, resulting in a value of $r>1$.

Table 4. Mean energy fluxes and mixing efficiency during the measurement period. Mixing efficiency in the entire inner Oslofjord is calculated by using values for work against buoyancy (Eq. 23) based on data from 2003 and 2009 where the result varied in the range 20 to $40 \mathrm{~kW}$. Estimates of energy loss between station S2 and S5 are based on Eq. (21) with a value of $f$ in the range 0.5 to 1.5.

\begin{tabular}{|c|c|c|c|c|c|}
\hline Method & $\begin{array}{l}\text { Energy flux at } \\
\text { station S2 }(\mathrm{kW})\end{array}$ & $\begin{array}{l}\text { Energy flux at } \\
\text { station S5 }(\mathrm{kW})\end{array}$ & $\begin{array}{l}\text { Energy loss between } \\
\text { S2 and S5 }(\mathrm{kW})\end{array}$ & Ratio $r$ (Eq. 22) & $\begin{array}{l}R_{f} \text { inside the } \\
\text { Drøbak sill (Eq. 23) }\end{array}$ \\
\hline Energy density method $F^{d}$ (Eq. 19) & 430 & 140 & $150 \pm 70$ & $35 \pm 15 \%$ & $0.05-0.09$ \\
\hline $\begin{array}{l}\text { Energy density method with } \\
\text { energy equipartition } F^{2 d}\end{array}$ & 360 & 100 & $160 \pm 50$ & $45 \pm 15 \%$ & $0.06-0.11$ \\
\hline Two-layer method $F^{\text {two }}$ (Eq. 19) & 385 & 55 & $275 \pm 25$ & $70 \pm 10 \%$ & $0.05-0.10$ \\
\hline Normal mode method $F^{m}$ (Eq. 18) & 155 & 30 & $95 \pm 15$ & $60 \pm 10 \%$ & $0.13-0.26$ \\
\hline Perturbation pressure method $F^{p}$ (Eq. (15)) & 185 & & & & $0.11-0.22$ \\
\hline
\end{tabular}




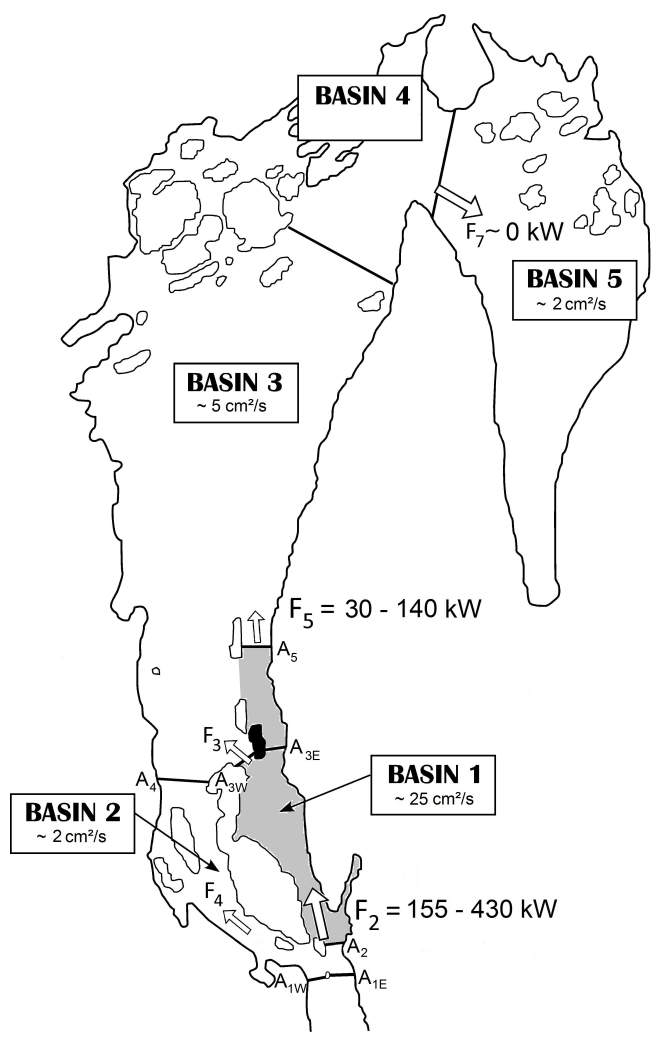

Fig. 13. Fluxes $F$ of internal wave energy entering and leaving the area just north of the Drøbak Sill (highest and lowest values from Table 4) are shown in a schematic map of the inner Oslofjord. The results from calculations at stations S2 and S5 are indicated with the highest and lowest result next to the arrows. The depth-averaged diffusivities (Eq. 22) between 90 and $125 \mathrm{~m}$ depth with unit $\mathrm{cm}^{2} \mathrm{~s}^{-1}$ are indicated for Basin 1, 2, 3 and 5. The area of increased turbulence production is shaded (between S2 and S5). The Aspond Island is marked with black. The cross sections from Table 3 are marked on the figure.

Estimates of energy flux based on energy density (Eqs. (19) or (20)) are 2-3 times higher than estimates based on perturbation pressure (Eqs. (15) or (18)). Equation (19) will overestimate the energy flux if parts of the energy are not moving with the group velocity $c_{g}$, but if only the vertical displacement fitted to the first mode at $\mathrm{S} 2$ is used to calculate the potential energy density (Eq. 11), the results get only 1-2\% lower. Equation (19) will also overestimate the energy flux if the internal wave is not purely a progressive wave but the sum of a wave propagating into the fjord and a reflected wave. Since the ratio between potential and kinetic energy density is higher than unity at S2 and lower at S5, this might be the case.

The estimates based on perturbation pressure (Eqs. (15) and (18)) allow for periods in time or depth intervals where the energy flux is directed out of the fjord, while Eq. (19) assumes that all fluxes of energy density are constantly directed into the fjord. If only the positive fluxes are included when Eq. (15) is used, the difference from the original results indicates that $5-10 \%$ of the energy propagates in the opposite direction at station S2. Energy equipartition $\left(E_{p}=E_{k}\right)$ is expected for a wave propagating like an interfacial wave. The ratio $\left\langle E_{p}\right\rangle_{H} /\left\langle E_{k}\right\rangle_{H}$ at $\mathrm{S} 2$ (Fig. 12a) shows that the internal wave is not a purely progressive wave for the whole period. Around spring tides, the ratio is as high as 2 . An alternative version of the energy density method, $F_{i}^{2 d}$, where the energy density is taken as $2 E_{k}$, is shown in Fig. $12 \mathrm{~b}-$ $\mathrm{d}$. The results show that the perturbation pressure method is sensitive to noise in the observations, and we interpret the estimates from Eqs. (19) and (20) as an upper limit and the estimates from Eqs. (15) and (18) as a lower limit for the energy fluxes.

\section{Baroclinic energy loss and vertical diffusivity}

In this section, energy fluxes found in Sect. 4 are used to identify areas in the fjord with enhanced turbulence production, and the differences between the diffusion coefficients calculated for the different basins are tentatively explained by these results.

\subsection{Estimates of baroclinic energy loss}

The energy fluxes at stations S2 and S5 have been calculated as described in Sect. 4.2. The baroclinic energy loss between the two stations is estimated as the difference between the energy flux into and out of the area on the east side of Håøya Island. The area in question is shaded with a grey colour in Fig. 13.

Analysis of the estimated energy fluxes at both stations S2 and S5 indicates that baroclinic energy propagates from the sill and into the fjord. By separating the positive and negative values of $\overline{p^{\prime} u^{\prime}}$ in Eq. (15), it is found that only a small fraction of the energy is reflected at S2 (possibly 5-10\%), and hence the remaining energy is lost within the inner fjord. The turbulence production in the Oslofjord can thus be estimated as the sum of the baroclinic energy flux away from the Drøbak Sill into the fjord and the dissipation over the sill. The observations in this study have not allowed for an estimate of baroclinic energy loss near the sill, between station S1 and S2. However, direct measurements of dissipation in this area from 2011 indicate that this can be of the same order of magnitude as the energy flux at station S2 (L. Arneborg, personal communication, 2011).

The total amount of energy flux into the inner fjord will also include flux on the western side of the Håøya Island, $F_{4}$ (Fig. 13). We believe that, since the cross-sectional area over the Drøbak Jetty on the west side is only about $10 \%$ of the total cross section at the Drøbak Sill (Aas and Endresen, 1999), the flow here will be more jet-like and produce mixing in a confined area, and not much of the energy will propagate away. There are no observations confirming this, and the 
unknown energy flux in the western inlet represents a major uncertainty in the present study. If we assume that $F_{4} \ll F_{2}$, we can say that 155 to $430 \mathrm{~kW}$ is dissipated or transformed to work against buoyancy in the inner fjord. For comparison, the total barotropic energy flux into the inner fjord is approximately $4000 \mathrm{~kW}$, estimated from the mean difference between low and high water of $0.3 \mathrm{~m}$ and the surface area of the inner fjord in Table 2. Not all of this is reflected, and the phase lag of approximately 5 minutes between the pressure sensors at stations S1 and S2 suggests a barotropic energy loss of about $250 \mathrm{~kW}$, using methods described by e.g. Stacy (2005) or Stigebrandt (1999).

No semidiurnal vertical oscillations are found in the internal motions near station S8 (see end of Sect. 3.2), and this indicates that the energy flux into Basin 5 is low, and that the loss of baroclinic energy must take place in Basins 1 to 4 .

The energy flux out of Basin 1 has to go on either side of the Aspond Island (Fig. 1b). We define $F_{3}$ as the energy flux from Basin 1 and into the western channel on the west side of the island (Fig. 13). We let the energy flux at station S2 $\left(F_{2}\right)$ represent the energy flux into the area east of the Håøya Island between stations S2 and S5. Likewise, we let the energy fluxes $F_{3}$ and $F_{5}$ represent the energy flux out of the same area. We assume that the energy flux in the eastern channel is approximately divided in two parts after station S3. The cross-sectional area of the passage on the west side of the Aspond Island $\left(\mathrm{A}_{3 W}\right)$ is about $60 \%$ of the area on the east side $\left(\mathrm{A}_{3 E}\right)$ (Table 3$)$. The latter area is leading to station S5. It is likely that some of the baroclinic energy is lost between stations S3 and S5 on the east side of the Aspond Island. Based on this, we assume that the energy flux $F_{3}$ is of the same order of magnitude as the energy flux at station S5. We can set up the following relationship:

$F_{3} \approx f F_{5}$

where $f$ is a factor possibly in the range 0.5 to 1.5 .

By applying values from Table 4 for $F_{2}$ and $F_{5}$ and using the relationship (Eq. 21) with $f=1$, we obtain a baroclinic energy loss $\left(F_{2}-F_{3}-F_{5}\right)$ in the range $95-275 \mathrm{~kW}$ by using the methods described by the Eqs. (15), (18), (19) and (20).

To test the effect of the assumption (Eq. 21), we have used $f=1.0 \pm 0.5$. Estimates of the same energy loss, based on Eqs. (18) and (21) with varying values of $f$, give results in the range $80-110 \mathrm{~kW}$.

The relative loss of baroclinic energy between S2 and S5 is

$r=\frac{F_{2}-F_{3}-F_{5}}{F_{2}}$

The results for Eq. (22), obtained by the different methods with $f=1$, are shown in Fig. 12d. Depending on the applied method, approximately $40-70 \%$ of the energy flux propagating into the inner fjord on the east side of Håøya Island is dissipated or transformed to work against buoyancy in the eastern channel within a distance of $10 \mathrm{~km}$ from the Drøbak Sill, and this is probably the most dissipative region of the fjord besides the sill area. The same ratio $r$, based solely on method Eq. (18) with $f=1.0 \pm 0.5$, obtains values in the range $50-70 \%$, indicating that the uncertainty introduced by the assumption $f=1.0 \pm 0.5$ is of the same order of magnitude as the uncertainty due to the choice of method.

It has been found in other fjords that most of the baroclinic energy loss occurs in the vicinity of the sill. Direct measurements of dissipation rates in the Gullmarfjord, where the tidal forcing is weaker than in the Oslofjord, indicated that about $77 \%$ of the dissipation took place above the sloping bottom closest to the sill (Arneborg et al., 2004).

In Knight Inlet, it is found by comparing direct measurements of dissipation rates with estimates of the barotropic energy loss over the sill that one third of the loss is dissipated near the sill (Klymak and Gregg, 2004).

\subsection{Vertical diffusivity}

We will now see how the estimated turbulence production is related to the observed vertical diffusivity.

The decrease of the density in closed basins during stagnant periods is a result of work against buoyancy. This work $W_{g}$ per time and volume unit can be expressed by

$W_{g}=-g K_{z} \frac{d \rho}{d z}$

where $K_{z}$ is the coefficient of vertical diffusion, and $\rho$ is the horizontal average of the density over the whole basin. $K_{z}$ can be calculated from the expression (Gade, 1970)

$K_{z}(z)=-\frac{-\int_{-H}^{z} Y\left(z^{\prime}\right) \frac{d \rho}{d t} d z^{\prime}}{Y(z) \frac{d \rho}{d z}}$

where $Y(z)$ is the horizontal area of the basin at depth $z$, and $d \rho / d z$ is the vertical density gradient at the same depth. This method is explained in more detail by Arneborg et al. (2004). Equation (24) contains two major sources of uncertainty: the time derivative $d \rho / d t$ and the vertical gradient $d \rho / d z$, both averaged over the horizontal area at each depth. The time derivative must be taken during stagnant periods, and the stratification must be stable. While the instantaneous diffusivity in the open oceans is highly variable, the temporal fluctuations below sill depth in a fjord are smaller. Still, the average value of $d \rho / d t$ will be sensitive to the choice of time interval. On shorter time scales, advection and vertical convection within the basin may even lead to positive values of $d \rho / d t$, thus making estimates of the mean diffusivity by Eq. (24) impossible.

Gade (1970) calculated $K_{z}$ from Eq. (24) in the Bunnefjord and in the Vestfjord (Fig. 2), based on measurements at station S8 and S5 respectively during several stagnant periods in 1963-1965. He found that the mean diffusivity between 90 and $125 \mathrm{~m}$ depth was $1.0 \pm 0.5 \mathrm{~cm}^{2} \mathrm{~s}^{-1}$ in 
the Bunnefjord and $7.6 \pm 4.1 \mathrm{~cm}^{2} \mathrm{~s}^{-1}$ in the Vestfjord. Our analysis of similar data from 2003 and 2009 gives for the same depth interval a mean diffusivity of $1.8 \pm 0.7 \mathrm{~cm}^{2} \mathrm{~s}^{-1}$ in the Bunnefjord (S8) and $4.9 \pm 0.5 \mathrm{~cm}^{2} \mathrm{~s}^{-1}$ in the Vestfjord (S5). The mean diffusivity in Basin 1 (S3) is found to be $25 \pm 2.0 \mathrm{~cm}^{2} \mathrm{~s}^{-1}$ and in Basin 2 (S4) $2.2 \pm 1.0 \mathrm{~cm}^{2} \mathrm{~s}^{-1}$. The depth-averaged diffusivities $\left\langle K_{z}\right\rangle_{H}$ between 90 and $125 \mathrm{~m}$ are marked for each basin in Fig. 13. It is noteworthy that the diffusivity is more than 4 times higher in Basin 1, where an enhanced turbulence production has been found, than in the other basins.

Stigebrandt (1976) used the diffusivities from Gade (1970) and estimated the work against buoyancy (Eq. 23) below $20 \mathrm{~m}$ depth inside the Drøbak Sill to be $50 \mathrm{~kW}$. Our analysis of data from 2003 and 2009 results in slightly smaller values of $W_{g}$ in the range $20-40 \mathrm{~kW}$.

The mixing efficiency $R_{f}$ of a basin can be expressed by

$R_{f}=\frac{\int_{V} W_{g} d V}{\Delta F}$

where $V$ is the volume of the basin, $W_{g}$ is defined by Eq. (23) and the net flux $\Delta F=F_{\text {in }}-F_{\text {out }}$ of internal wave energy into the volume is taken as an estimate of the turbulence production.

Results from Eq. (25) for the entire Oslofjord, based on present estimates of $W_{g}$ (Eq. 23) and the total turbulence production (Sect. 5.1), are listed in Table 4. The results are in the range $0.05-0.11$ if the flux is calculated from methods based on energy density (Eqs. (19) or (20)). If the energy flux is obtained from the perturbation pressure ((12) or (14)), the mixing efficiency $R_{f}$ increases to $0.11-0.26$. Stigebrandt (1976) estimated the same efficiency to be 0.05 by using Eq. (20). Only the spring tide was then considered since his energy flux was a sum of the tidal constituents. In the present study, the most efficient mixing is found during neap tides when the energy flux is at its minimum. We believe that, during more energetic periods of the spring-neap cycle, more of the energy of the internal tides is transferred to processes like e.g. horizontal eddies near the sill, rather than to vertical mixing. One might expect that a period with increased energy flux would lead to a period with increased work against buoyancy. However, by looking at the deep waters of S5 (figure not shown), no signs are found of a direct relationship between the baroclinic energy loss between S2 and S5 and the change of density on shorter timescales (days). We think this is because the mixing may be a result of internal waves that release parts of their energy both locally and elsewhere in the fjord.

The fate of the $30-60 \%$ of the baroclinic energy that is not lost between S2 and S5 is not known, but it seems like this remaining energy is very important for the vertical mixing in the less energetic parts of the inner fjord, since mixing efficiency is expected to be higher for these parts. Bjerkeng et al. (1978) found that the diffusivity calculated from observations of a passive tracer in the middle of the Vestfjord
(Basin 3) was one order of magnitude lower than the diffusivity calculated from the budget method (Eq. 24), and Stigebrandt (1979) suggested that this was because the diffusivity was higher around the basin borders where the breaking of internal waves is assumed to take place.

\section{Summary and final remarks}

Phase speeds of internal waves in the Oslofjord have been determined from observations of the vertical displacement of density surfaces within the pycnocline close to the sill depth of $20 \mathrm{~m}$, by using the correlation method (Sect. 3.1). The observed range of $1.2-1.5 \mathrm{~m} \mathrm{~s}^{-1}$ inside the Drøbak Sill agrees well with the theoretical range $0.8-1.5 \mathrm{~m} \mathrm{~s}^{-1}$ found for a twolayer model, and the agreement indicates that the first internal mode dominates inside the Drøbak Sill close to sill depth (Sect. 3.1).

The stronger density stratification in the lower layer outside the sill gives a much deeper mode- 1 maximum in the vertical displacement amplitude, and the observed phase speed of approximately $0.6 \mathrm{~m} \mathrm{~s}^{-1}$ out of the fjord, based on phase lag of the vertical displacement around $20 \mathrm{~m}$ depth, is probably associated with a mode-2 wave (Sect. 3.1, Fig. 4).

An envelope method to determine the amplitude of the observed vertical displacements is described, and the results reveal that there is a linear relationship between the amplitude of the vertical displacement in the pycnocline and the tidal forcing, at both stations S2 and S5 inside the Drøbak Sill (Sect. 3.2, Fig. 9). These vertical displacements are associated entirely with a mode- 1 internal wave. The observed ratio between the amplitudes of the internal wave in the pycnocline and the surface elevation is in the range $38 \pm 6$ at a distance of $1 \mathrm{~km}$ inside the Drøbak Sill, and $11 \pm 2$ at $10 \mathrm{~km}$. The two-layer model of Stigebrandt (1970) predicts a ratio in the range $31 \pm 15$, based on the density stratification and the geometry of the fjord, which coincides with the observed ratio close to the sill.

The greatest vertical displacements of density surfaces inside the sill, however, are found at $40 \mathrm{~m}$ depth (Sect. 3.2, Fig. 8a). These internal waves are not entirely associated with a first-mode internal tide, but are rather associated with higher internal modes controlled by stratification. Vertical displacements observed below the pycnocline seem to be associated with jet-like currents at sill depth and are not a linear response to the tidal currents. When the inflowing current is positioned just above the sill depth, a jet seems to form that depresses the density surfaces below even further down (Sect. 3.2, Fig. 5). This process depends on the vertical current profile and is not directly dependent on the tidal forcing. As a result, the amplitude of the vertical displacement, at for instance $40 \mathrm{~m}$ depth at station S2, is not correlated with the amplitude of the surface elevation.

The frequency spectrum of the internal tides is very similar to the spectrum of the barotropic tide. In addition to 
the dominating semidiurnal tide, the harmonic overtides contribute significantly in the Oslofjord (Sect. 3.2, Fig. 10).

The vertical density gradients estimated from the sensors at the moorings may have errors of up to $50 \%$, which is probably why the ratio between the depth-averaged potential and kinetic baroclinic energy densities obtains the mean value and standard deviation $1.3 \pm 0.4$ at station $\mathrm{S} 2$ (Sect. 4.1, Figs. 11-12).

The total barotropic energy flux to the inner fjord is estimated as approximately $4000 \mathrm{~kW}$ (Sect. 1), while $250 \mathrm{~kW}$ of this flux may be lost close to the Drøbak Sill (Sect. 5.1). The energy flux of the internal wave propagating from the Drøbak Sill into the inner fjord on the east side of the Håøya Island has been estimated by five different methods (Sect. 4.2, Table 4). The results vary in the range $155-430 \mathrm{~kW}$, which is $4-10 \%$ of the barotropic flux. The energy flux obtained from observed internal tidal energy density and estimated group speed (Eqs. (19)-(20)) is 2-3 times higher than the energy flux found from perturbation pressure and baroclinic velocity (Eqs. (15) and (18)) (see Table 4). This can partly be explained by the fact that methods based on perturbation pressure allow for negative energy flux in some periods of time or in parts of the depth interval. But only $5-10 \%$ of the energy flux calculated from Eq. (15) at S2 is reflected, so another possibility is that not all of the observed energy density is propagating away from the sill, or that the group velocity of the energy transport is lower than the first-mode phase speed. Xing and Davis (2011) found in a model study of a sill fjord with a sill depth of $30 \mathrm{~m}$ that the baroclinic energy flux was reduced to $20-30 \%$ when a second sill was introduced 1.5 to $2.5 \mathrm{~km}$ further into the fjord, and that standing internal tides were generated between the sills. It could be that the relatively high levels of perturbation energy density observed at S2 are due to standing waves. The database available offers no definite answer as to which method gives the most realistic picture, so we can only conclude that different methods give different results for the baroclinic energy fluxes in the Oslofjord (Sect. 4.2).

By fitting normal modes to the baroclinic pressure and velocity, it is found that about $13 \%$ of the energy flux at station $\mathrm{S} 2$ is carried by the second internal mode, and that all of the second-mode energy is dissipated between S2 and S5 (Sect. 4.2).

Semidiurnal internal tides are not found in the Bunnefjord, indicating that the baroclinic energy is low in this innermost basin. Gade (1970) found that the mean diffusivity is five times lower in this basin $\left(1.0 \pm 0.5 \mathrm{~cm}^{2} \mathrm{~s}^{-1}\right)$ than in the Vestfjord $\left(7.6 \pm 4.1 \mathrm{~cm}^{2} \mathrm{~s}^{-1}\right)$ where our observations imply a higher baroclinic energy level. This ratio between the mean diffusivities of the two basins is also confirmed by our calculations based on more recent data $\left(1 \mathrm{~cm}^{2} \mathrm{~s}^{-1}\right.$ and $\left.5 \mathrm{~cm}^{2} \mathrm{~s}^{-1}\right)$. Approximately $40-70 \%$ of the energy flux of the internal wave propagating from the Drøbak Sill into the inner fjord on the east side of the Håøya Island is lost within a distance of $10 \mathrm{~km}$ from the sill (Sect. 5.1), and the mean diffusivity below $90 \mathrm{~m}$ depth in this area is more than four times higher than in the rest of the fjord (Sect. 5.2).

Mixing efficiency based on energy fluxes calculated from the energy density method (Sect. 5.1) results in values for $R_{f}$ in the range $0.05-0.11$, while the perturbation pressure method gives values in the range 0.11-0.26 (Sect. 5.2).

To summarize, we have in this paper quantified the relationship between the amplitudes of the barotropic and baroclinic tides, and found that the baroclinic energy density associated with the mode- 1 semidiurnal tides is a function of the barotropic energy density. Furthermore, we have shown that a significant portion of this baroclinic energy is lost in an area with enhanced diffusivity. It can finally be added that an on-going numerical study of the Oslofjord indicates that it may be possible to quantify the relationship between the vertical diffusivity and the tides.

Acknowledgements. This project - Tidally-induced turbulent mixing in a silled fjord (Pro. no. 184944) - has been supported by the Norwegian Research Council.

Thanks are due to Jan Magnusson and the crew on board the RV Trygve Braarud for their assistance during the field work, as well as to Göran Broström and Lars Petter Røed for constructive discussions and suggestions.

Edited by: J. M. Huthnance

\section{References}

Aas, E. and Endresen, Ø.: Accuracy of simplified transport estimations in narrow sea straits, Ocean Dynam., 51, 441-451, 1999.

Afanasyev, Y. D. and Peltier, W. R.: On breaking internal waves over the sill in Knight Inlet, Proc. Roy. Soc. Lnd. A, 457, 2700-2825, 2001.

Armi, L. and Farmer, D.: Stratified flow over topography: bifurcation fronts and transition to the uncontrolled state, Proc. Roy. Soc. Lnd. A, 458, 513-538, 2002.

Arneborg, L., Janzen, C., Liljebladh, B., Rippeth, T. P., Simpson, J. and Stigebrandt, A.: Spatial variability of diapycnal mixing and turbulent dissipation rates in a stagnant fjord basin, J. Phys. Oceanogr., 34, 1679-1691, 2004.

Arneborg, L. and Liljebladh, B.: The internal Seiches in Gullmar Fjord. Part I: Dynamics, J. Phys. Oceanogr., 31, 2549-2566, 2001a.

Arneborg, L. and Liljebladh, B.: The internal Seiches in Gullmar Fjord. Part II: Contribution to basin water mixing, J. Phys. Oceanogr. , 31, 2567-2574, 2001b.

Arneborg, L. and Liljebladh, B.: Overturning and dissipation caused by baroclinic tidal flow near the sill of a fjord basin, J. Phys. Oceanogr., 39, 2156-2174, 2009.

Cottier, F., Inall, M., and Griffiths, C.: Seasonal variations in internal wave energy in a Scottish sea loch, Ocean Dynam. 54, 340 347, 2004.

Farmer, D. and Armi, L.: Stratified flow over topography: the role of small-scale entrainment and mixing in flow establishment, Proc. Roy. Soc. Lnd. A, 455, 3221-3258, 1999. 
Farmer, D. M. and Freeland, H. J.: The physical oceanography of fjords, in: Progress in Oceanography, Vol. 12, edited by: Angel, M. V. and O'Brien, J. J., Pergamon Press, Oxford, 147-219, 1983.

Farmer, D. M. and Smith, J. D.: Nonlinear internal waves in a fjord, in: Hydrodynamics of Estuaries and Fjords, edited by: Nihoul, J., Elsevier, 465-493, 1978.

Farmer, D. M. and Smith, J. D.: Generation of lee waves over the sill in Knight Inlet, in: Fjord Oceanography, edited by: Freeland, H. J., Farmer, D. M., and Levings, C. D., Plenum Press, 259-269, 1979.

Farmer, D. M. and Smith, J. D.: Tidal interaction of stratified flow with a sill in Knight Inlet, Deep-Sea Res., 27A, 239-254, 1980.

Fjeldstad, J. E.: Internal waves of tidal origin, Geofys. Publ., 25, 73 pp., 1964.

Freeland, H. J., Farmer, D. M. and Levings, C. D. (eds.): Fjord Oceanography, NATO Conference Series, Vol. IV:4, Plenum Press, New York, USA, 715 pp., 1980.

Gade, H. G: The Oslofjord and its pollution problems, Investigations 1962-1965, Report no. 2, Hydrography (in Norwegian), NIVA report OR-0191c, 163 pp., 1967.

Gade, H. G.: Hydrographic investigations in the Oslofjord, a study of water circulation and exchange processes, Geophys. Inst. Div. A, Rep 24, 1970.

Gade, H. and Edwards, A.: Topographic influence on determination of one-dimensional vertical diffusivity in sea basins, Geophys. Inst., Univ. Bergen, Rep. No. 73, 20 pp., 1995.

Gade, H. G., Edwards, A., and Svendsen, H.: Coastal Oceanography, NATO Conference Series, Vol. IV, Plenum Press, New York, USA, 582 pp., 1983.

Gargett, A. E.: Turbulence measurements through a train of breaking internal waves in Knight Inlet, BC, in: Fjord Oceanography, edited by: Freeland, H. J., Farmer, D. M., and Levings, C. D., Plenum Press, 277-281, 1979.

Gill, A. E.: Atmosphere-Ocean Dynamics, Academic Press, San Diego, CA, USA, 662 pp., 1982.

Gill, A. E. and Clarke, A. J.: Wind-induced upwelling, coastal currents and sea-level changes, Deep-Sea Research, 21, 325-345, 1974.

Inall, M. E.: Internal wave induced dispersion and mixing on a sloping boundary, Geophys. Res. Let., 36, L05604, doi:10.1029/2008GL036849, 2009.

Inall, M. E. and Rippeth, T. P.: Dissipation of tidal energy and associated mixing in a wide fjord, Environm. Fluid Mech., 2, 219240, 2002.

Inall, M., Cottier, F. Griffiths, C., and Rippeth, T.: Sill dynamics and energy transformation in a jet fjord, Ocean Dynam., 54, 307-314, doi:10.1007/s10236-003-0059-2, 2004.

Inall, M. E. and Gillibrand, P. A.: The physics of mid-latitude fjords: a review, Geological Society, London, UK, Special Publications 344, 17-34, 2010.

Johnsson, M., Green, J. A., and Stigebrandt, A.: Baroclinic wave drag from two closely spaced sills in a narrow fjord as inferred from basin water mixing, J. Geophys. Res., 112, C11002, doi:10.1029/2006JC003694, 2007.

Kaartvedt, S., Røstad, A., and Klevjer, T. A.: Sprat Sprattus sprattus can exploit low oxygen waters for overwintering, Mar. Ecol. Prog. Ser., 390, 237-249, doi:10.3354/meps08196, 2009.
Klymak, J. M. and Gregg, M. C.: Tidally generated turbulence over the Knight Inlet Sill, J. Phys. Oceanogr., 34, 1135-1151, 2004.

Kullenberg, G.: Measurements of horizontal and vertical diffusion in coastal waters, Dept. Phys. Oceanogr., Univ. Copenhagen, Rep. No. 3, 66 pp., 1968.

Kullenberg, G.: Results of diffusion experiments in the upper region of the sea, Dept. Phys. Oceanogr., Univ. Copenhagen, Rep. No. 12, 66 pp., 1971.

Kunze, E., Rosenfeld, L. K., Carter, G. S., and Gregg, M. C.: Internal waves in Monterey submarine canyon, J. Phys. Oceanogr., 32, 1890-1913, 2002.

Larsen, T. L., Olaussen, S., Sundvoll, B., and Heeremans, M.: The Permo-Carboniferous Oslo Rift through six stages and 65 million years, Episodes, 31, 52-58, 2008.

Lepland, A., Bøe, R., Lepland, A., and Totland, O.: Monitoring the volume and lateral spread of disposed sediments by acoustic methods, Oslo Harbor, Norway, J. Enviriron. Man., 90, 11, 3589-3598, 2009.

Osborne, T. R.: Estimates of the local rate of vertical diffusion from dissipation measurements. J. Phys. Oceanogr., 10, 83-89, 1980.

Stacey, M. W.: Review of the partition of tidal energy in five Canadian fjords, J. Coast. Res., 21, 731-746, 2005.

Stashchuk, N., Inall, M., and Vlasenko, V.: Analysis of supercritical stratified tidal flow in a Scottish fjord, J. Phys. Oceanogr., 37, 1793-1810, 2007.

Stigebrandt, A.: Vertical diffusion driven by internal waves in a sill fjord, J. Phys. Oceanogr., 6, 486-495, 1976.

Stigebrandt, A.: Observational evidence for vertical diffusion driven by internal waves of tidal origin in the Oslofjord, J. Phys. Oceanogr., 9, 435-441, 1979.

Stigebrandt, A.: Some aspects of tidal interaction with fjord constrictions, Estuar. Coast. Mar. Sci., 11, 151-166, 1980.

Stigebrandt, A.: Resistance to barotropic tidal flow in straits by baroclinic wave drag, J. Phys. Oceanogr., 29, 191-197, 1999.

Stigebrandt, A. and Aure, J.: Vertical mixing in basin waters of fjords, J. Phys. Oceanogr., 19, 917-926, 1989.

Svendsen, H.: Mixing and exchange processes in estuaries, fjords and shelf waters, in: The Role of Freshwatwer Outflow in Coastal Marine Ecosystems, NATO ASI Series, Vol. G7, editor S. Skreslet, Springer-Verlag Berlin Heidelberg, 13-45, 1986.

Syvitski, J. P. M., Burrell, D. C., and Skei, J. M.: Fjords - Processes and Products, Springer-Verlag, New York Inc., 379 pp., 1987.

Sælen, O. H.: Temperature variations and heat transport in the Nordfjord, Bergen Museums årbok 1946-1947, Nat. Vit. rekke, 6, 28 pp., 1948.

Thorpe, S. A.: The Turbulent Ocean. Cambridge University Press, 439 pp., 2005.

Xing, J. and Davies A. M.: On the interaction of internal tides over two adjacent sills in a fjord, J. Geophys. Res., 116, C04022, doi:10.1029/2010JC006333, 2011.

Zeilon, N.: On the tidal boundary waves and related hydrodynamical problems. Kungl. Svenska Vetenskapsakademiens Handlingar, 47, 46 pp., 1912.

Zeilon, N.: On the seiches of the Gullmar Fjord, Svenska Hydrog. - Biolog. Komm. Skrifter, 5, 1-17, 1913. 